Check for updates

Cite this: Chem. Sci., 2017, 8, 4904

\title{
Metal exchange in lithiocuprates: implications for our understanding of structure and reactivity $\dagger$
}

\begin{abstract}
Andrew J. Peel, Ryan Ackroyd and Andrew E. H. Wheatley (D) *
New reagents have been sought for directed ortho cupration in which the use of cyanide reagents is eliminated. CUOCN reacts with excess TMPLi (TMP $=2,2,6,6$-tetramethylpiperidide) in the presence of limited donor solvent to give crystals that are best represented as $(\mathrm{TMP})_{2} \mathrm{Cu}_{0.1} \mathrm{Li}_{0.9}(\mathrm{OCN}) \mathrm{Li}_{2}(\mathrm{THF}) \mathrm{B}$, whereby both Lipshutz-type lithiocuprate $(\mathrm{TMP})_{2} \mathrm{Cu}(\mathrm{OCN}) \mathrm{Li}_{2}(\mathrm{THF}) 8 \mathrm{a}$ and trinuclear $(\mathrm{TMP})_{2}(\mathrm{OCN}) \mathrm{Li}_{3}(\mathrm{THF})$ $8 \mathrm{~b}$ are expressed. Treatment of a hydrocarbon solution of $\mathrm{TMP}_{2} \mathrm{CuLi}$ 9a with LiOCN and THF gives pure 8a. Meanwhile, formation of $8 \mathrm{~b}$ is systematized by reacting $\left(\mathrm{TMPH}_{2}\right) \mathrm{OCN} 10$ with TMPH and $n$ BuLi to give $(\mathrm{TMP})_{2}(\mathrm{OCN}) \mathrm{Li}_{3}(\mathrm{THF})_{2}$ 11. Important to the attribution of lower/higher order bonding in lithiocuprate chemistry is the observation that in crystalline 8, amide-bridging $\mathrm{Cu}$ and $\mathrm{Li}$ demonstrate clear preferences for di- and tricoordination, respectively. A large excess of Lewis base gives an 8-membered metallacycle that retains metal disorder and analyses as $(\mathrm{TMP})_{2} \mathrm{Cu}_{1.35} \mathrm{Li}_{0.65} 9$ in the solid state. NMR spectroscopy identifies 9 as a mixture of $(\mathrm{TMP})_{2} \mathrm{CuLi} 9 \mathrm{a}$ and other copper-rich species. Crystals from which the structure of 8 was obtained dissolve to yield evidence for $8 \mathrm{~b}$ coexisting in solution with in situ-generated 9a, 11 and a kinetic variant on 9a ( $i-9 a)$, that is best viewed as an agglomerate of TMPLi and TMPCu. Moving to the use of DALi (DA = diisopropylamide), $(\mathrm{DA})_{2} \mathrm{Cu}_{0.09} \mathrm{Li}_{0.91}(\mathrm{Br}) \mathrm{Li}_{2}(\mathrm{TMEDA})_{2} 12$ $\left(T M E D A=N, N, N^{\prime}, N^{\prime}\right.$-tetremethylethylenediamine) is isolated, wherein $(\mathrm{DA})_{2} \mathrm{Cu}(\mathrm{Br}) \mathrm{Li}_{2}(\mathrm{TMEDA})_{2} \quad 12 \mathrm{a}$ exhibits lower-order $\mathrm{Cu}$ coordination. The preparation of $(\mathrm{DA})_{2} \mathrm{Li}(\mathrm{Br}) \mathrm{Li}_{2}(\mathrm{TMEDA})_{2}$ 12b was systematized using $\left(\mathrm{DAH}_{2}\right) \mathrm{Br}$, DAH and $n$ BuLi. Lastly, metal disorder is avoided in the $2: 1$ lithium amide : Lipshutztype monomer adduct $(\mathrm{DA})_{4} \mathrm{Cu}(\mathrm{OCN}) \mathrm{Li}_{4}(\mathrm{TMEDA})_{2} 13$.
\end{abstract}

Received 30th March 2017

Accepted 28th April 2017

DOI: $10.1039 / \mathrm{c} 7 \mathrm{sc} 01423 f$

rsc.li/chemical-science

\section{Introduction}

Interest in methods for refining the regioselective functionalization of aromatics by using more selective bases has grown significantly since the inception ${ }^{\mathbf{1}}$ of what have become known as 'synergic bases'.2 These heterobimetallic systems - in their simplest form $\mathrm{R}_{m} \mathrm{M}\left(\mathrm{NR}_{2}{ }_{2}\right)_{n} \mathrm{AM}(\mathrm{R}=$ organyl; $m=0,2,3 ; \mathrm{M}=$ less polarizing metal; $\mathrm{NR}^{\prime}{ }_{2}=$ amide; $n=1,2,3$; $\mathrm{AM}=$ more polarizing (alkali) metal) - have afforded new levels of reactivity, ${ }^{3}$ regioselectivity ${ }^{4}$ and functional group tolerance ${ }^{5}$ not hitherto available through traditional main group organometallic bases. Recently, a fruitful area of synergic base chemistry that has developed has involved directed cupration using lithium cuprate reagents. ${ }^{6}$ The structural variability manifest in lithium cuprate chemistry, which derives in part from the potential to enhance reactivity by introducing an alkali metal salt, highlights the need to better understand structural variability in synergic systems. The corresponding elucidation of synergic bases was initially dominated by crystallographic

Department of Chemistry, University of Cambridge, Lensfield Road, Cambridge, CB2 1EW UK. E-mail: aehw2@cam.ac.uk; Fax: +44(0) 1223336362

$\dagger$ Electronic supplementary information (ESI) available. CCDC 1540280-1540286. For ESI and crystallographic data in CIF or other electronic format see DOI: $10.1039 / \mathrm{c} 7 \mathrm{sc} 01423 \mathrm{f}$ determination. ${ }^{7}$ However, their heterobimetallic composition has led to the need for solution analysis to establish the nature of competition between structure retention of the heterobimetallic moiety versus the cooperative action of individually monometallic reagents ${ }^{8}$ and the permutations for dynamic deaggregation/recombination. ${ }^{7 c, 9}$

First developed 50 years ago, ${ }^{\mathbf{1 0}}$ lithium cuprates have been subsequently modified in two main ways. First, lithium amidocuprates have been developed, offering often unique reactivities as well as the potential of the amido group as a nontransferable ligand and as a chiral auxiliary., ${ }^{\mathbf{9 1 1}}$ Second, yield enhancements have been sought by combining so-called Gilman lithium cuprates $\left(\mathrm{R}_{2} \mathrm{CuLi}\right)$ with lithium salts. For the deployment of $\mathrm{LiCN}$ as the latter, ${ }^{12}$ the resulting cuprates $\left(\mathrm{R}_{2} \mathrm{Cu}(\mathrm{CN}) \mathrm{Li}_{2}\right)$ were coined Lipshutz cuprates and spectroscopic studies suggested the possibility that transfer of cyanide to $\mathrm{Cu}$ would give a higher order (tricoordinate) metal. ${ }^{13}$ However, the alternative of retention of lower order (dicoordinate) copper was suggested on theoretical, ${ }^{\mathbf{1 4}}$ spectroscopic $^{\mathbf{1 5}}$ and, more recently, $\mathrm{X}$-ray diffraction ${ }^{\mathbf{1 6}}$ grounds. The isolation and characterization of lithium cyanocuprates 1a-c, which were prepared using amidolithium reagents with $\mathrm{CuCN}$, revealed the bonding characteristics of $\mathrm{Cu}$ in systems that could demonstrate either higher or lower order structural properties. In line with 
theoretical expectations, ${ }^{14}$ lower order $(\mathrm{TMP}){ }_{2} \mathrm{Cu}(\mathrm{CN}) \mathrm{Li}{ }_{2}(\mathrm{~L})(\mathrm{L}=$

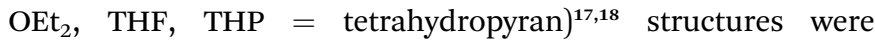
observed crystallographically, with agglomeration giving essentially planar dimers based on lithium-nitrogen cores (Scheme 1). The observation that, whilst in other respects 1a-c pertained to Lipshutz cuprate characteristics, they lack a $\mathrm{Cu}-\mathrm{CN}$ interaction led to investigation of the generality of this motif. To this end (TMP) ${ }_{2} \mathrm{Cu}(\mathrm{X}) \mathrm{Li}_{2}(\mathrm{~L})\left(\mathrm{X}=\mathrm{Cl}\right.$ 2, Br 3, I 4, $\mathrm{L}=\mathrm{OEt}_{2} \mathbf{2 a}-\mathbf{4 a}$, THF $\mathbf{2 b - 4 b}$ ) were isolated (Scheme 1) $\cdot{ }^{19,20}$ As with the previously reported cyanide structures, these revealed lower order $\mathrm{Cu}$ in the solid state. The extension of monoatomic bridges to the field of triatomic inorganic anions was achieved by the development of thiocyanatocuprates. These utilize $\mathrm{SCN}^{-}$in place of $\mathrm{CN}^{-}$and formed (TMP) ${ }_{2} \mathrm{Cu}(\mathrm{SCN}) \mathrm{Li}_{2}(\mathrm{~L})\left(\mathrm{L}=\mathrm{OEt}_{2} \mathbf{5 a}\right.$, THF $\mathbf{5 b}$, THP 5c), which demonstrated 8-membered metallacyclic (LiSCN $)_{2}$ cores supported by 6-membered $\mathrm{N}_{3} \mathrm{CuLi}_{2}$ rings in the solid state (Scheme 2). In these structures, significant solvent effects were noted through the adoption of either planar, boat or chair conformers for the 8-membered core depending on whether the cuprate was additionally stabilized by $\mathrm{OEt}_{2}$, THF or THP, respectively. ${ }^{21}$

The recent observation that cyanide-incorporating Lipshutz cuprates exhibit solvent-controlled conversion to their Gilman counterparts $^{7 c, h}$ by the abstraction of $\operatorname{LiCN}^{22}$ has been superceded by the discovery that this process is likely to be responsible for the in situ creation of active species in solution. ${ }^{23}$ This has reinvigorated interest in the properties of lithium amidocuprates and it has been noted that the ability of bimetallics of the type $\left(\mathrm{R}_{2} \mathrm{~N}\right)_{2} \mathrm{CuLi}$ to dimerize, coupled with the acknowledged issue of metal exchange between $\mathrm{Li}$ and $\mathrm{Cu}$, as elucidated by van Koten and co-workers, ${ }^{16 a, b, 24}$ means that the field of Gilman cuprate chemistry is closely interwoven with that of copper-nitrogen metallacycles. These have been observed to

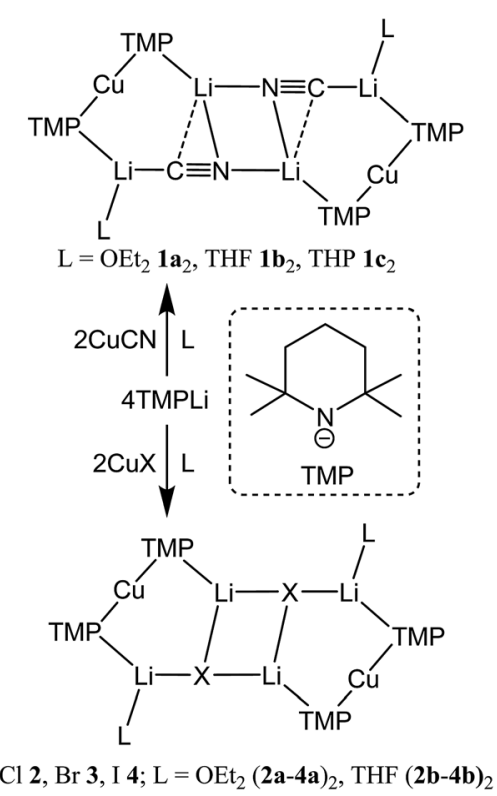

Scheme 1 Formation of the dimers of cyano- and halogenocuprates $1-4$.

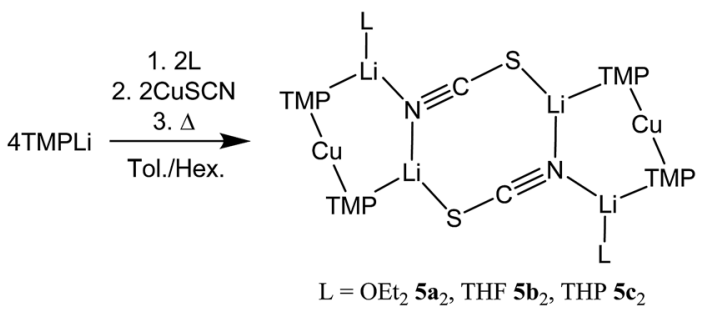

Scheme 2 Formation of the dimers of thiocyanatocuprates 5 .

constitute tetrameric ketimides, ${ }^{25}$ hydrazides, ${ }^{25}$ phosphinimides $^{26}$ mixed amides/guanidinates ${ }^{27}$ and amides ${ }^{9}$ with the last of these ligand-types also supporting 3D clusters. ${ }^{28}$ Copper amides, first prepared a century ago $^{29}$ and more recently the focus of intense study, ${ }^{11 a, 30}$ have proven to be synthetically important, with solid state tetramers shown to deaggregate and participate in modified Ullmann amination ${ }^{31}$ with arenes in the presence of 1,10-phenanthroline. ${ }^{9}$ Meanwhile, Gilman lithium amidocuprates have been established to constitute the active species in directed aromatic cupration. ${ }^{17}$ However, synthetic studies having established that as-prepared Gilman cuprates are ineffectual, the need to convert Lipshutz(-type) cuprates to their Gilman counterparts in solution has been shown. ${ }^{23}$

The current work sees further efforts to study the use of polyatomic inorganic salts in lithium amidocuprate chemistry, through the deployment of the rarely used cyanate ligand. This accesses a range of new lithium cyanatocuprates. Metal disorder in some examples of these new materials sheds important new light on the predilection of $\mathrm{Cu}$ for lower/higher order structure formation. Advances are also reported in our understanding of the solution behaviour of lithium cuprates.

\section{Results and discussion}

\section{Synthesis and solid state analysis}

$\mathrm{Cu}\left(\mathrm{NO}_{3}\right)_{2}\left(\mathrm{H}_{2} \mathrm{O}\right)_{3}$ was reacted sequentially with $\operatorname{LiOAc}\left(\mathrm{H}_{2} \mathrm{O}\right)_{2}$, and LiOCN (see ESI $\dagger$ ). The addition of $\mathrm{SO}_{2}$ gave a green solution from which CuOCN 7 precipitated. ${ }^{32}$ The ability to prepare 7 offers the possibility of analyzing the cyanate analogue of recently reported (TMP) ${ }_{2} \mathrm{Cu}(\mathrm{SCN}) \mathrm{Li}_{2}(\mathrm{THF}) .{ }^{21} \mathrm{~A}$ hexane solution of TMPLi was therefore reacted with CuOCN in a $2: 1$ ratio in the presence of THF ( 1 eq. wrt $\mathrm{Cu}$ ). This gave a modest yield of crystalline blocks. IR spectroscopy showed a strong peak at 2208 $\mathrm{cm}^{-1}$ and X-ray diffraction pointed to the formulation (TMP) $)_{2}$ $\mathrm{M}(\mathrm{OCN}) \mathrm{Li}_{2}$ (THF) but revealed disorder at the TMP-bridging metal site. The optimal crystallographic refinement suggests $\mathrm{M}=\mathrm{Cu}_{0.1} \mathrm{Li}_{0.9}$, and therefore a $1: 9$ co-crystalline mixture of $(\mathrm{TMP})_{2} \mathrm{Cu}(\mathrm{OCN}) \mathrm{Li}_{2}(\mathrm{THF}) \quad 8 \mathrm{a}$ and $(\mathrm{TMP})_{2}(\mathrm{OCN})$ $\mathrm{Li}_{3}$ (THF) 8b (Scheme 3 and Fig. 1).

The X-ray diffraction structure of 8 reveals dimerization based on an 8-membered metallacyclic (LiOCN) $)_{2}$ core that incorporates a 3-coordinate $\mathrm{Li}$ centre (Li2). This core is supported by two 6-membered $\mathrm{N}_{3} \mathrm{MLi}_{2}$ rings, within which the coordination sphere of Li3 is completed by THF. However, in contrast to the previously noted THF-solvated thiocyanate $5 \mathbf{b}_{2},{ }^{21}$ 


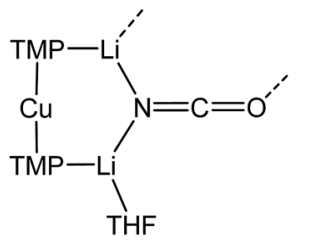

$8 \mathbf{a}$<smiles>COC1=NN([AlH])[Al]1C</smiles>

$8 \mathbf{b}$

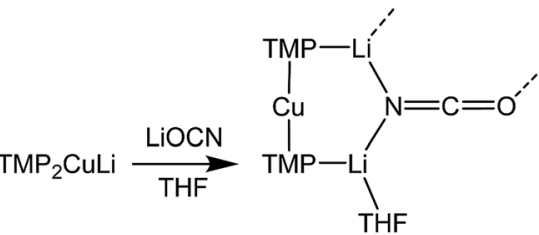

$8 \mathrm{a}$

Scheme 4 Synthesis of 8 a by a route that eliminates the possibility of LiOCN abstraction by TMPLi.

N1-Li1-N2 angle of $186.6(5)^{\circ}$. The observation of a N3-Li1 2.597(11) A distance suggests a weak interaction between these two centres and yields a motif reminiscent of intercepted ladder-type structures reported in the past for amidolithium aggregates. $^{33}$

Reasoning that the depletion of copper in $\mathbf{8}$ may have been caused by the rapid sequestration of in situ formed LiOCN by TMPLi, we attempted to prepare $\mathbf{8 a}$ by a route in which these two components were not present simultaneously. A solution of donor-free $\mathrm{TMP}_{2} \mathrm{CuLi}$ (9a) was therefore prepared using hydrocarbon solvent. This was combined with LiOCN and THF was introduced, later being replaced with hexane. The resulting solution gave radiating fans of crystals (Scheme 4). X-ray crystallography reveals the expected centrosymmetric dimer of $\mathbf{8 a}$ (ESI, Fig. S3 $\dagger$ ). Though pure $\mathbf{8} \mathbf{a}_{2}$ and its counterpart component of $\mathbf{8}_{2}$ are not strictly isostructural, the differences in molecular structure are small. In particular, marginally reduced planarity in pure $\mathbf{8 a}_{2}$ when compared to its partner component of $\mathbf{8}_{2}$, results in a larger value of mean deviation from the plane of $0.205 \AA$ (excluding THF and TMP-carbons, $c f$. $0.085 \AA$ for $\mathbf{8} \mathbf{a}_{2}$ in $\mathbf{8}_{2}$ ). These observations suggest that although weak, the N3 $\cdots$ Li1 transannular interaction in component $\mathbf{8 b}_{2}$ of $\mathbf{8}_{2}$ exerts an influence, via crystal packing, over minor component $\mathbf{8} \mathbf{a}_{2}$ in the same structure.

To attempt the synthesis of pure $\mathbf{8 b}$, two different routes were pursued. The documented use of a secondary ammonium
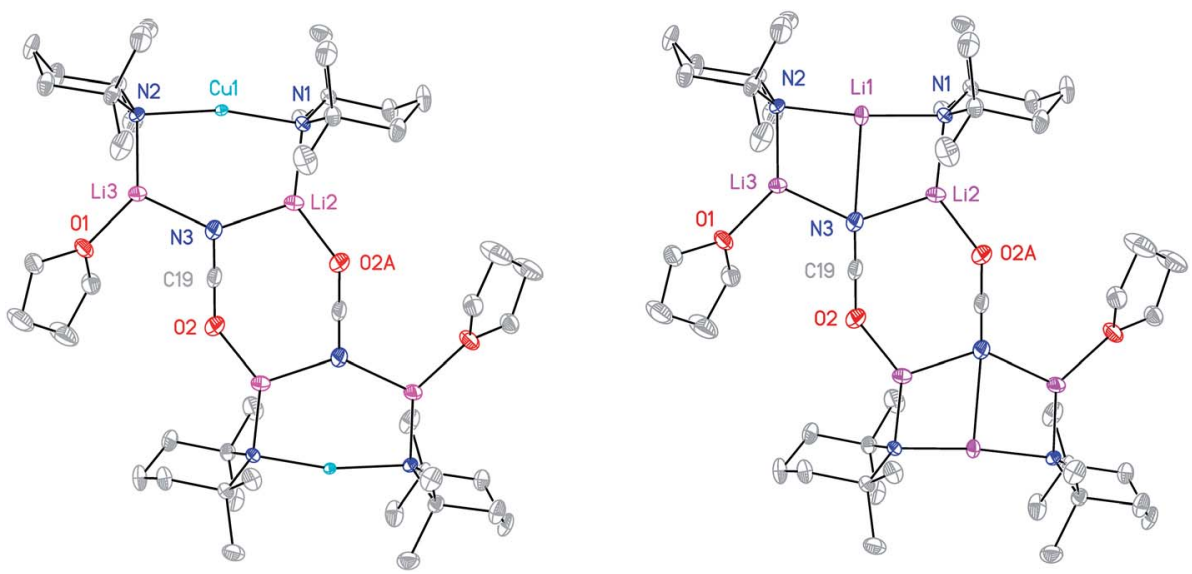

Fig. 1 Molecular structures of $8 \mathrm{a}_{2}$ (left) and $8 \mathrm{~b}_{2}$ (right, $30 \%$ probability and with $\mathrm{H}$-atoms omitted). Selected bond lengths $(\AA \AA)$ and angles $\left({ }^{\circ}\right)$ : $\mathrm{N} 1-$ Cu1 1.968(11), N2-Cu1 2.029(11), N3 ‥Cu1 2.93(1), N1-Li1 1.970(16), N2-Li1 2.009(16), N3-Li1 2.597(11), N1-Li2 1.969(3), N2-Li3 1.935(3), N3Li2 2.056(4), N3-Li3 2.040(4), O2-Li2A 1.904(3), O2-C19 1.211(3), N3-C19 1.168(3), N1-Cu1-N2 167.3(4), N1-Li1-N2 173.4(6), N1-Li1-N3 94.5(5), N2-Li1-N3 92.1(5). 


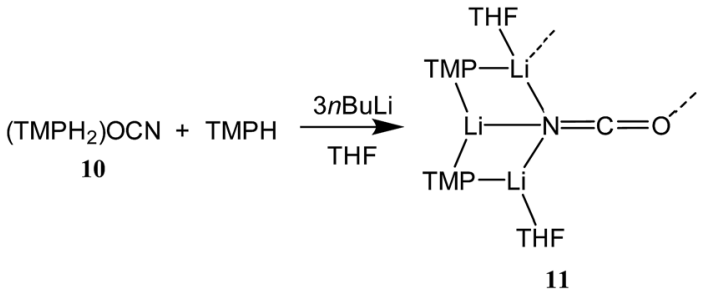

Scheme 5 Lithiation of 10 and TMPH in bulk THF to give 11.

salt to generate a mixed lithium halide-lithium amide aggregate in situ $u^{34}$ led us to synthesize cyanate salt $\left(\mathrm{TMPH}_{2}\right) \mathrm{OCN} \mathbf{1 0}$ (see ESI $\dagger$ ). This was then reacted with TMPH and $n \mathrm{BuLi}$ in a $1: 1: 3$ ratio. The deployment of bulk THF as reaction medium followed by its removal and replacement with hexane gave crystals. Alternatively, direct combination of LiOCN with TMPLi $(1: 2)$ in THF followed by recrystallization from hexane provided the same product. ${ }^{1} \mathrm{H}$ NMR spectroscopy revealed these to comprise TMP and THF in a $1: 1$ ratio and IR spectroscopy gave a strong peak at $2207 \mathrm{~cm}^{-1}$. X-ray diffraction confirmed the formulation (TMP) $)_{2}(\mathrm{OCN}) \mathrm{Li}_{3}(\mathrm{THF})_{2} \mathbf{1 1}$ (Scheme 5), with dimerization occurring in the same way as with $\mathbf{8 b}$ (Fig. 1). The observation that this O-Li interaction is longer in 11 (O3A-Li2 $1.968(3)^{\circ}$; Fig. 2) than in $\mathbf{8 b}$ is explained by additional THF rendering Li2 tetracoordinate. The result of this THF-inclusion on the wider structure is significant. With Li2 now pseudo-tetrahedral, $\mathbf{1 1}_{2}$ adopts a chair conformation in which only the core (LiOCN $)_{2}$ ring occupies a single plane. In contrast to the structure of $\mathbf{8}_{2}$ (ESI, Fig. S1 $\dagger$ ) the lithiumnitrogen heterocycles and the THF molecules now deviate significantly above or below this central plane. Peripheral to the structure core, the geometry of the $(\mathrm{NLi})_{3}$ arrangement in $\mathbf{1 1}$ imitates that in $\mathbf{8 b}$, though the expanded N1-Li1-N2 reflex angle of $196.61(16)^{\circ}$ allows a transannular interaction (N3-Li1 $=2.198(3) \AA$ ) shorter than that in $\mathbf{8 b}$ and similar to other $\mathrm{N}-\mathrm{Li}$ bonds in the structure. A further point of contrast between $\mathbf{8 b}$ and $\mathbf{1 1}$ lies in the orientation of the amido groups. The ability of these to adopt different orientations for steric reasons has been noted previously in lithiocuprate systems. ${ }^{18}$ In the current work, the TMP ligands in $\mathbf{8 b}$ mimic the amido groups in lithiocuprate 5b whereby the 6-membered rings of the two TMP groups bonded to a $\mathrm{Cu}$ centre are each oriented away from one another and so lie flat or endo, endo with respect to the (LiOCN) $)_{2}$ structure core (Fig. 1). However, the inclusion of additional THF appears instrumental in causing one TMP ligand to adopt an upright orientation in $\mathbf{1 1},{ }^{35}$ giving an exo, endo ligand pattern instead (Fig. 2).

The ability to isolate 8 proved solvent dependent; an equivalent synthesis in bulk THF (Scheme 3) yielded a crystalline material, 9, which analyses in the solid state as an 8-membered metallacyclic copper-rich material $\mathrm{TMP}_{m+n} \mathrm{Cu}_{m} \mathrm{Li}_{n}$ (in 9, $m+n=$ 4; Fig. 3). The contribution of different species to the overall

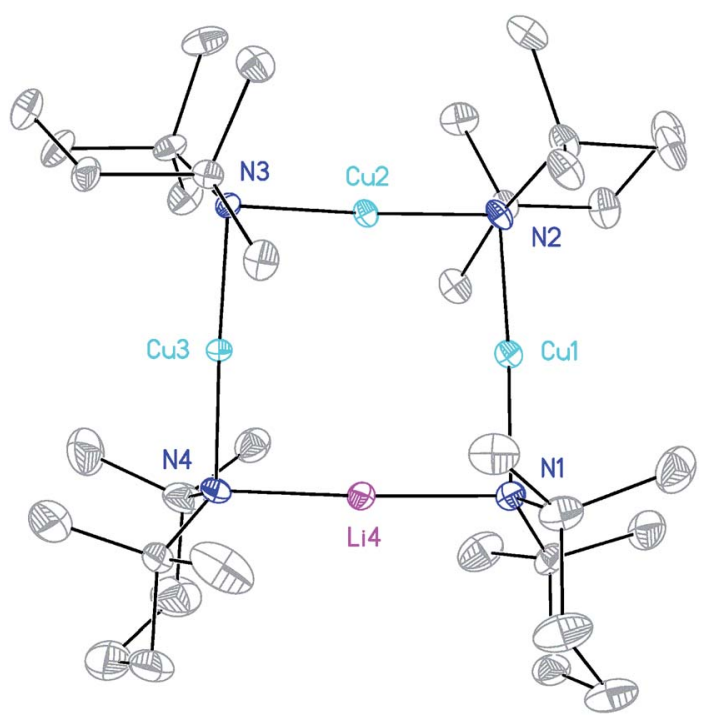

Fig. 3 Molecular structure of 9 (30\% probability and with $\mathrm{H}$-atoms omitted, major metal occupancies shown). Selected bond lengths (Å): N1-M1 1.953(3), N2-M1 1.973(3), N2-M2 1.931(3), N3-M2 1.922(3), N3-M3 1.961(3), N4-M3 1.955(3), N4-M4 2.001(4), N1-M4 2.018(4).
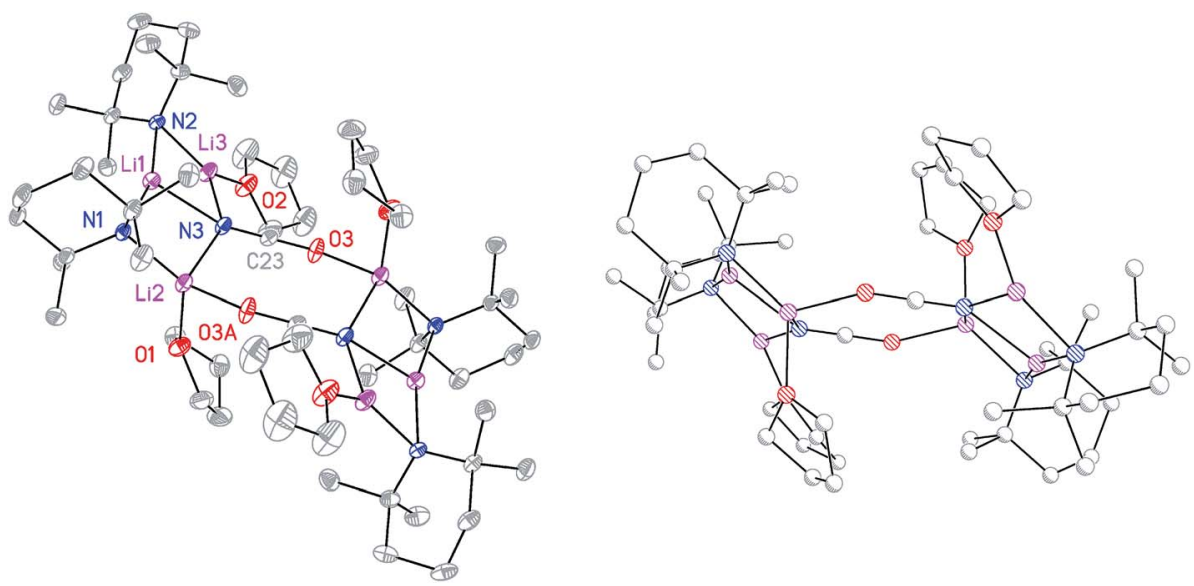

Fig. 2 Molecular structure of $11_{2}\left(30 \%\right.$ probability and with $\mathrm{H}$-atoms omitted). Selected bond lengths $(\AA)$ and angles $\left({ }^{\circ}\right)$ : N1-Li1 2.029(3), N2-Li1 2.088(3), N3-Li1 2.198(3), N1-Li2 2.030(3), N2-Li3 1.930(3), N3-Li2 2.228(3), N3-Li3 2.036(3), O3A-Li2 1.968(3), O3-C27 1.208(2), N3-C27 1.172(2), N1-Li1-N2 163.39(16), N1-Li1-N3 100.56(12), N2-Li1-N3 95.39(12). 


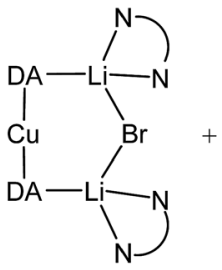

12a

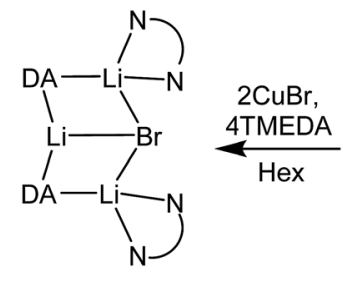

12b

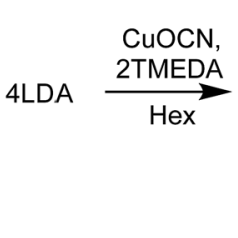

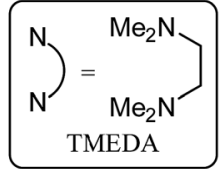

13

Scheme 6 Anion-dependent synthesis of $12 \mathrm{a} / \mathrm{b}$ and 13 .

composition of 9 could only be elucidated by solution studies (see below). The structure shown in Fig. 3 can be rationalized in conjunction with the observation of that of $\mathbf{8}$; the excess THF solvating NCOLi and abstracting it from Lipshutz-type 8 to give 9. This view explains the deficiency of $\mathrm{Cu}$ in 8.

We next investigated the use of stronger Lewis bases as solvents for lithiocuprates. TMEDA $\left(N, N, N^{\prime}, N^{\prime}\right.$-tetremethylethylenediamine) was introduced to $2: 1$ mixtures of amidolithium and $\mathrm{Cu}(\mathrm{I})$ reagents. Using DAH (= diisopropylamine), crystals were obtained incorporating different inorganic anions. As with prior work in the field of lithiocuprate chemistry, the use of $\mathrm{CuBr}$ as copper source enabled the isolation of a product containing both amide (in this case DA) and Lewis base (in this case TMEDA). This was achieved by treating DAH and TMEDA with $n$ BuLi and CuBr in a 2:2:2:1 ratio in hydrocarbon media. ${ }^{1} \mathrm{H}$ NMR spectroscopy suggested that the resulting isolable material incorporated DA and TMEDA in a $1: 1$ ratio, pointing to possible isolation of the Lipshutz-type cuprate $(\mathrm{DA})_{2} \mathrm{Cu}(\mathrm{Br})$ $\mathrm{Li}_{2}(\mathrm{TMEDA})_{2}$. X-ray diffraction revealed a more complex picture, displaying disorder at the amide-bridging metal site, with the best crystallographic refinement suggesting a $\mathrm{Cu}_{0.09} \mathrm{Li}_{0.91}$ population, i.e. a ca. $1: 9$ co-crystalline mixture of Lipshutz-type $(\mathrm{DA})_{2} \mathrm{Cu}(\mathrm{Br}) \mathrm{Li}_{2}(\mathrm{TMEDA})_{2}$ 12a and (DA $)_{2} \mathrm{Li}(\mathrm{Br}) \mathrm{Li}_{2}(\mathrm{TMEDA})_{2}$ 12b (collectively 12, Scheme 6).

X-ray diffraction for $\mathbf{1 2}$ reveals a monomer, with the bromide bridging two TMEDA-solvated $\mathrm{Li}^{+}$centres to yield a 6-membered $\mathrm{N}_{2} \mathrm{MLi}_{2} \mathrm{Br}$ core. For $\mathrm{M}=\mathrm{Cu}$ (Fig. 4, left) this is a motif known in bis(amido)lithiocuprate chemistry, though previously the use of monodentate Lewis bases yielded dimers, ${ }^{19-21}$ with the exception of $\left(\mathrm{Ph}_{2} \mathrm{~N}\right)_{2} \mathrm{Cu}\left(\mathrm{NPh}_{2}\right) \mathrm{Li}_{2}\left(\mathrm{OEt}_{2}\right)_{2} \cdot{ }^{11 a}$ In contrast to 8 , but in common with previous reports of Lipshutz-type bis(amido) lithiocuprates incorporating 6-membered metallacycles, the $\mathrm{Cu}$ centre in 12a is essentially linear ( $\left.\mathrm{N} 1-\mathrm{Cu} 1-\mathrm{N} 2 \mathrm{176.0}(7)^{\circ}\right)$ and the Cu1 $\cdots$ Br1 distance $(3.073(10) \AA)$ is non-bonding. The dicoordinate (lower order) nature of $\mathrm{Cu}$ is highlighted by comparison with $\mathbf{1 2 b}$, in which Li1 is located significantly closer to Br1 $(2.624(14) \AA)$ than $\mathrm{Cu} 1$ is in 12a. As with 8b, this displacement of the alkali metal results in a transannular interaction, the reflex N1-Li1-N2 angle being 208.4(8) .

The structure of 12b bears comparison with the highly unusual lithium amide-lithium chloride adduct $(\mathrm{DA})_{2} \mathrm{Li}(\mathrm{Cl})$ $\mathrm{Li}_{2}$ (TMEDA) ${ }_{2}$ (ref. 34) and, in the same way that the synthesis of amidolithium-cyanatolithium $\mathbf{8 b}$ could be systematized using the cyanate salt 10, it proved possible to achieve a synthesis of pure $12 \mathbf{b}$ by reacting $\left(\mathrm{DAH}_{2}\right) \mathrm{Br}$ with $n \mathrm{BuLi}$ in the presence of TMEDA (Scheme 7 and ESI, Fig. S4 $\dagger$ ). The removal of metal disorder to target pure cuprate 12a was also attempted; DAH was treated with $n \mathrm{BuLi}$ and TMEDA and then with CuOCN in

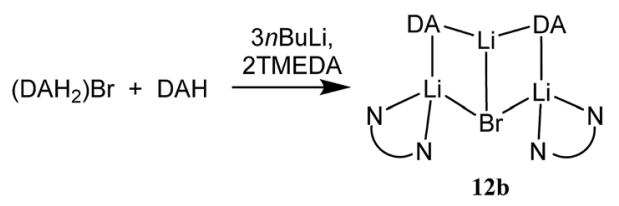

Scheme 7 Lithiation of $\left(\mathrm{DAH}_{2}\right) \mathrm{Br}$ and $\mathrm{DAH}$ to give pure $12 \mathrm{~b}$
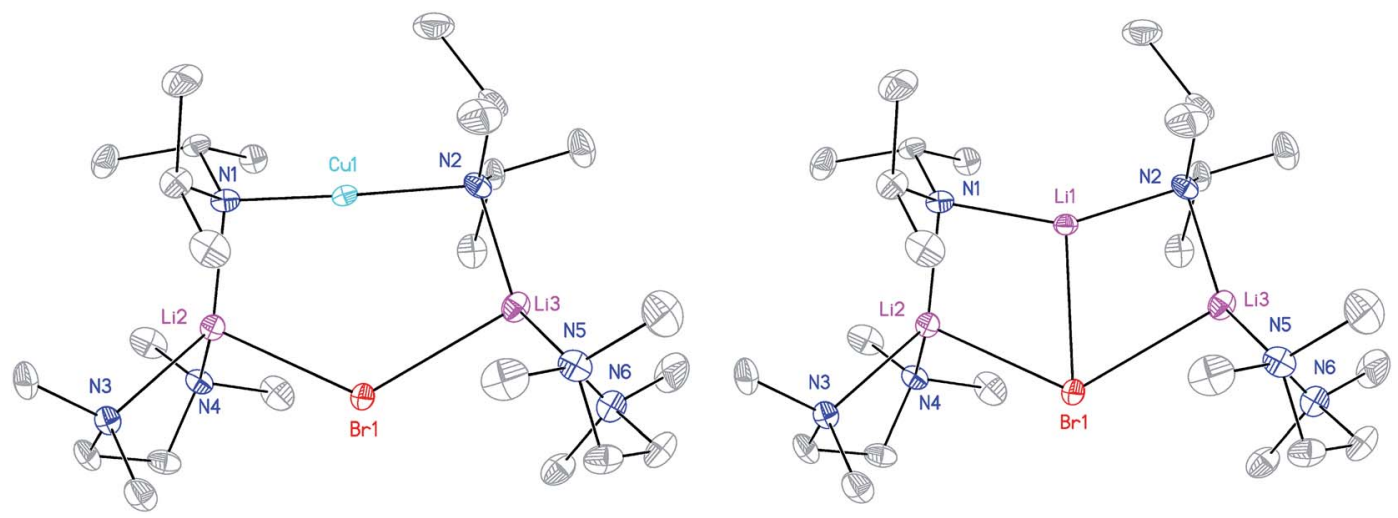

Fig. 4 Molecular structure of the monomers of $12 \mathrm{a}$ and $12 \mathrm{~b}$ (30\% probability and with $\mathrm{H}$-atoms omitted). Selected bond lengths $(\AA)$ and angles

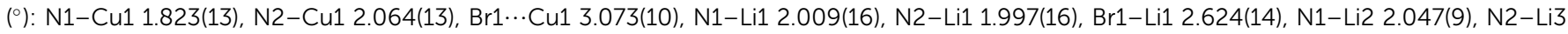
2.022(10), Br1-Li2 2.640(8), Br1-Li3 2.688(9), N1-Cu1-N2 176.0(7), N1-Li2-Br1 101.1(4), N2-Li3-Br1 102.5(4), Li2-Br1-Li3 125.5(3). 
(a)

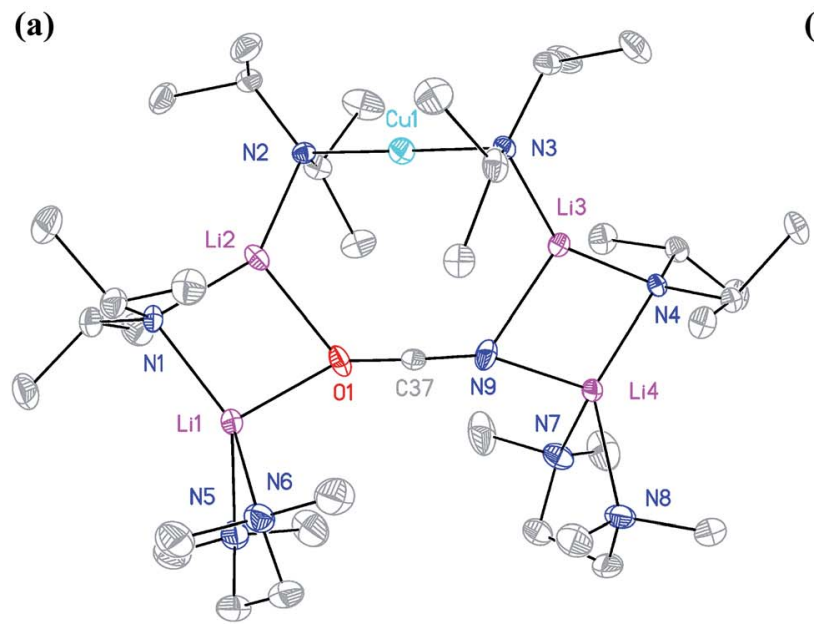

(b)

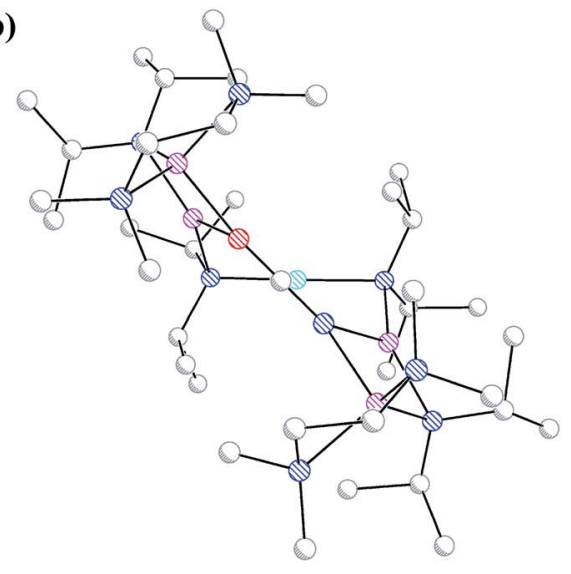

Fig. 5 (a) Molecular structure of $13\left(30 \%\right.$ probability and with minor disorder and $\mathrm{H}$-atoms omitted). Selected bond lengths $(\AA)$ and angles $\left({ }^{\circ}\right)$ : N2-Cu1 1.910(2), N3-Cu1 1.909(2), N2-Li2 2.058(5), N1-Li2 1.991(5), N1-Li1 2.044(5), N3-Li3 2.053(5), N4-Li3 1.985(5), N4-Li4 2.048(5), N9Li3 2.159(6), N9-Li4 2.026(5), O1-Li2 2.137(6), O1-Li1 2.009(5), N9-C37 1.202(4), O1-C37 1.205(4), N2-Cu1-N3 179.09(11), N2-Li2-O1 117.7(2), N3-Li3-N9 117.4(2), Li2-O1-C37 126.3(2), Li2-O1-Li1 81.6(2), Li2-N1-Li1 84.4(2), N1-Li1-O1 98.0(2), Li3-N9-C37 121.9(2), Li3-N9-Li4 81.3(2), Li3-N4-Li4 85.1(2), N4-Li4-N9 97.9(2); (b) 13 viewed along the C37…Cu1 vector and with the N3-Cu1-N2 unit oriented horizontally.

hexane. The resulting crystalline material yielded NMR spectroscopic data that pointed to the presence of DA and TMEDA in a $2: 1$ ratio, while IR spectroscopy revealed a cyanate peak at $2208 \mathrm{~cm}^{-1}$. These data were inconsistent with the structure type exhibited by 12a and, in due course, X-ray diffraction revealed 13 to be a $2: 1$ adduct between DALi and the cuprate (DA) $2^{-}$ $\mathrm{Cu}(\mathrm{OCN}) \mathrm{Li}_{2}(\mathrm{TMEDA})_{2}$. Crystallography pointed to a complete lack of metal disorder at the DA-bridging position (Fig. 5a). It is immediately apparent that the behaviour of the cyanate ligand contrasts with that noted in 8a, where the bonding mode adopted by the ligand yielded both a 6-membered cuprate ring and facilitated dimerization. This variability in cyanate coordination is similar to that noted recently for the thiocyanate ligand $^{21}$ and, in the current case, the cyanate ligand participates in the formation of an 8-membered $\mathrm{N}_{2} \mathrm{CuLi}_{2} \mathrm{NCO}$ ring. The capture of two molecules of DALi gives 4-membered $\mathrm{N}_{2} \mathrm{Li}_{2}$ and $\mathrm{NOLi}_{2}$ rings. Whereas 8a incorporates an essentially flat $\mathrm{N}_{2} \mathrm{CuLi}_{2} \mathrm{~N}$ ring, the 8-membered metallacycle in $\mathbf{1 3}$ deviates significantly from planarity, allowing the DALi molecules to project above and below the plane incorporating the $\mathrm{N}-\mathrm{Cu}-\mathrm{N}$ unit and the cyanate C-centre (Fig. 5b).

\section{NMR spectroscopy}

Interpretation of the convoluted solution behaviour for the systems described above has been attempted. It was anticipated that compound $\mathbf{8}$ would yield two species in solution - $\mathbf{8 a}$ and $\mathbf{8 b}$. In the event, NMR spectroscopy of the bulk material could not be reconciled with this simple model of metal disorder. ${ }^{7} \mathrm{Li}$ NMR spectroscopy, for example, revealed multiple solution species (Fig. 6). With NMR spectra of 9a reported previously, ${ }^{19}$ its presence at as a minor component of this mixture at $\delta 0.90 \mathrm{ppm}$ was easily established. To aid the assignment of other components, the spectroscopy of (TMP $)_{2}(\mathrm{OCN}) \mathrm{Li}_{3}(\mathrm{THF})_{2}$ 11 was examined. The reproducible in situ reformation of a limited amount of TMPH in all TMP-based systems is attributed to the presence of trace moisture in the deuterated solvent in spite of its storage over molecular sieves $(3 \AA)$. This notwithstanding, ${ }^{13} \mathrm{C}$ NMR spectroscopy revealed the existence of $\mathbf{1 1}$ as the only species observable in solution (Fig. 7).

Returning to the ${ }^{7} \mathrm{Li}$ NMR spectrum of bulk 8, the broad features at $\delta 2.18$ and $1.41 \mathrm{ppm}$ can now be accounted for by 11 and, by comparison with an authentically prepared sample (see ESI $†$ ), 9b, respectively, leaving two signals to be identified at $\delta 1.64 \mathrm{ppm}$ and at $\delta 0.48 \mathrm{ppm}$. To assign the first of these, ${ }^{1} \mathrm{H}$ NMR spectroscopy was used. Firstly, THF notwithstanding, the ${ }^{1} \mathrm{H}$ NMR spectrum of $\mathbf{1 1}$ was dominated by three singlets, at $\delta 1.76,1.57$ and $1.39 \mathrm{ppm}$ in a $1: 2: 1$ integral ratio. HSQC spectroscopy identified these as belonging to TMP-Me groups,

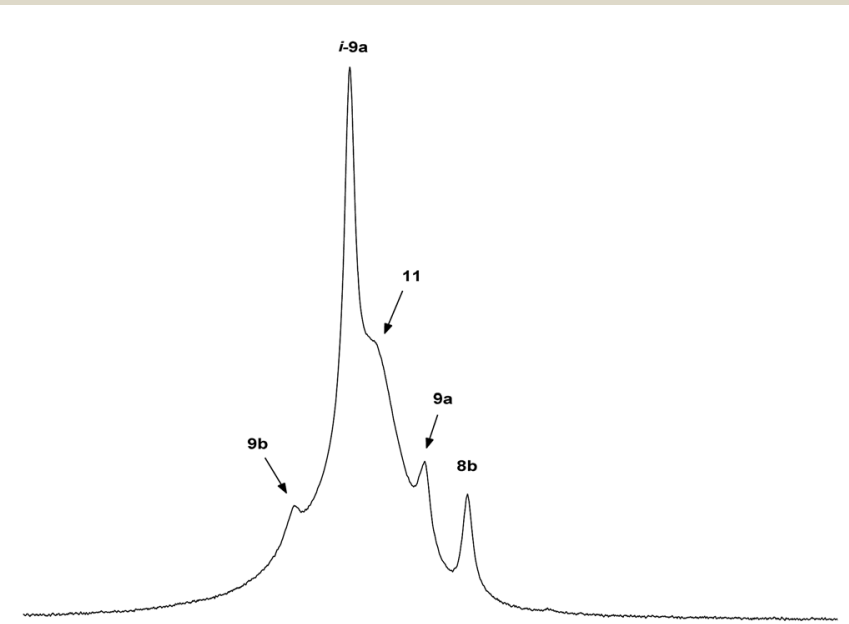

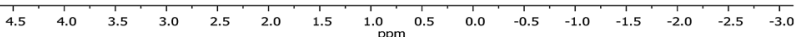

Fig. $6{ }^{7}$ Li NMR spectrum of bulk 8 in $C_{6} D_{6}$. 


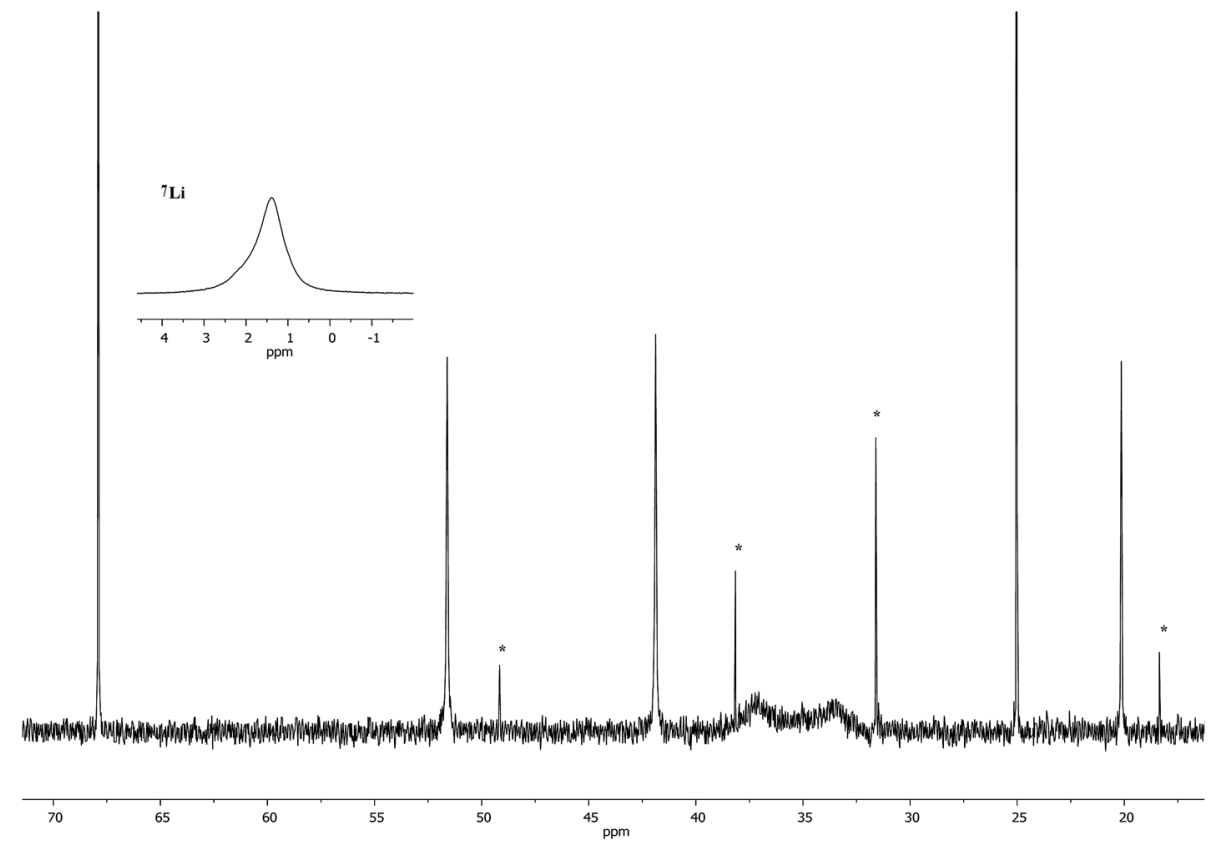

Fig. $7{ }^{13} \mathrm{C}$ NMR spectrum of 11 in $\mathrm{C}_{6} \mathrm{D}_{6}$ (main); ${ }^{7} \mathrm{Li}$ NMR spectrum (inset). ${ }^{*} \mathrm{TMPH}$.

and comparison with the TMP-Me resonances in authentic samples of 9a-c (see ESI $\dagger$ ) revealed that each of the aforementioned singlets falls within the expected chemical shift range for these compounds. Overall, these data suggest an isomeric variant of the previously reported dimer of Gilman cuprate 9a (Fig. 8a). ${ }^{19}$ We propose inverse-9a (i-9a); a tetranuclear metallacycle incorporating adjacent pairs of $\mathrm{Li}$ and $\mathrm{Cu}$ centres (Fig. 8b) best viewed as resulting from the agglomeration of dimers of TMPLi $\mathbf{9 b}$ and TMPCu 9c. The arrangement of $\boldsymbol{i}$-9a yields three distinct TMP environments (Fig. 8). We hypothesise $\boldsymbol{i}$-9a to be a kinetic product since it results formally from the catenation of dinuclear units of $\mathbf{9 b}$ and $\mathbf{9 c}$ without requiring the formation of Gilman cuprate 9a. This thesis suggests that under suitable conditions, $\boldsymbol{i}$-9a will rearrange to $\mathbf{9} \mathbf{a}_{2}$. To test this, a typical sample of bulk 8 was heated to reflux and allowed to stand at room temperature. Fine needles crystallized, which were shown to be (thermodynamically preferred) Gilman cuprate by NMR spectroscopy.

Lastly, the minor signal at $\delta 0.48 \mathrm{ppm}$ in Fig. 6 most logically belonged to either $\mathbf{8 a}$ or $\mathbf{8 b}$. The spectroscopic analysis of pure 8a was therefore carried out. This revealed a system whose behaviour paralleled that of previously reported $5 a^{21}{ }^{21}$ with the deposition of a fine white powder occurring upon sample

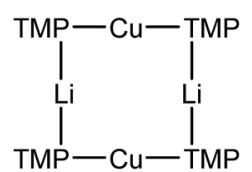

(a)

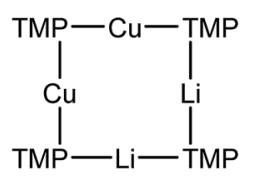

(b)
Fig. 8 (a) The dimer of 9a reveals one distinct TMP environment whereas (b) dimers of $9 \mathrm{~b}$ and $9 \mathrm{c}$ can aggregate to give $i-9 \mathrm{a}$, which reveals three. dissolution in $\mathrm{C}_{6} \mathrm{D}_{6}$ (presumed LiOCN in this case). Except for the presence of THF, the signals matched those of $9 \mathrm{a}\left({ }^{7} \mathrm{Li}\right.$ NMR $\delta 0.90 \mathrm{ppm}$ ). This suggests that the signal at $\delta 0.48 \mathrm{ppm}$ in Fig. 6 is due to $\mathbf{8 b}$ not $\mathbf{8 a}$.

Both the metal disorder in single crystal $\mathbf{8}$ and the presence of multiple products in the bulk reaction mixture are unusual features in amidocuprate systems. However, they can be explained by reactions (1)-(3) below. In (1), CuOCN reacts with 9b to expel LiOCN. This is rapidly sequestered in (2) at a rate competitive with (3). Remaining $\mathbf{9 b}$ reacts with in situ formed $\mathbf{9 c}$ (3) to then generate any compound in the series $\mathrm{TMP}_{m+n} \mathrm{Cu}_{m} \mathrm{Li}_{n}$ (e.g. $\boldsymbol{i}-9 \mathrm{a})$. The failure to isolate $\boldsymbol{i}-\mathbf{9 a}$ in previous lithium amidocuprate work is best explained by a combination of the kinetic properties of $\boldsymbol{i}-\mathbf{9 a}$ and the ability of $9 \mathrm{a}$ (but not $\boldsymbol{i}-\mathbf{9 a}$ ) to also be generated by the dissociation of Lipshutz-type cuprates.

Formation of TMPCu 9c

$$
\underset{\mathbf{9} \mathbf{b}}{\mathrm{MPLi}}+\mathrm{CuOCN} \rightarrow \underset{\mathbf{9}}{\mathrm{T}} \underset{\mathrm{MPC}}{\mathrm{C}}+\mathrm{LiOCN}
$$

Formation of $\mathrm{TMP}_{2} \mathrm{Li}_{3} \mathrm{OCN}(\mathrm{THF})_{2} \mathbf{1 1}$

$$
2 \mathrm{TMPLi}+\mathrm{LiOCN}+2 \mathrm{THF} \rightarrow \mathrm{TMP}_{2} \mathrm{Li}_{3} \mathrm{OCN}(\mathrm{THF})_{2}
$$

Formation of $\mathrm{TMP}_{2} \mathrm{CuLi}$ 9a and $\boldsymbol{i}$-9a

$$
\underset{\mathbf{9 b}}{\mathrm{TMPi}}+\underset{\mathbf{9 c}}{\mathrm{TMPCu}} \rightarrow \underset{\mathbf{9 a} \text { and } \boldsymbol{i}-\mathbf{9 a}}{\mathrm{TMP}_{2} \mathrm{CuLi}}
$$

Moving to the behaviour of lithium amidocuprates in more polar reaction media, the $2: 1$ reaction of TMPLi and CuOCN in THF followed by recrystallization from hexane gave $\mathbf{9}$, which crystallographic refinement indicated to be rich in $\mathrm{Cu}$ (Fig. 3), 


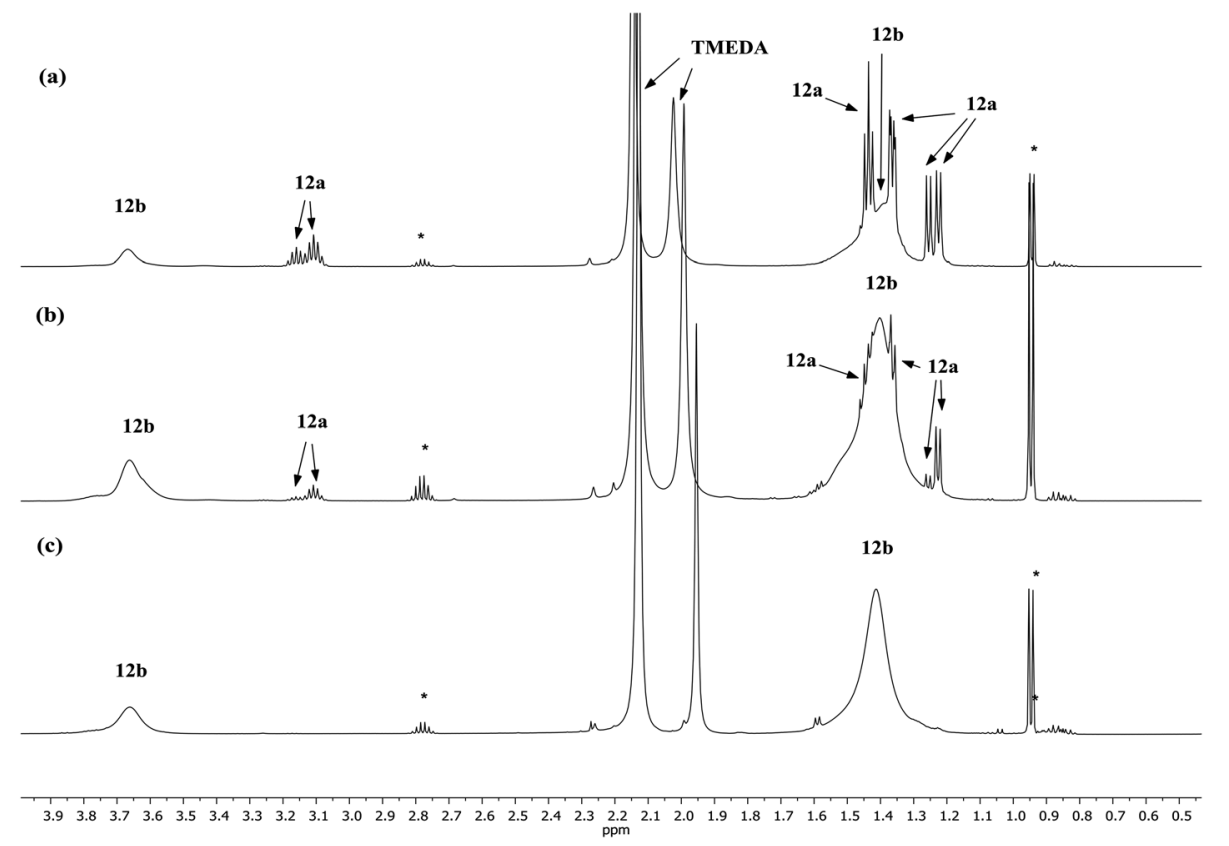

Fig. $9{ }^{1} \mathrm{H}$ NMR spectra in $\mathrm{C}_{6} \mathrm{D}_{6}$ of (a) 12 (b) 12 (c) $12 \mathrm{~b}$. *DAH.

though the individual contributions of $\mathrm{TMP}_{m+n} \mathrm{Cu}_{m} \mathrm{Li}_{n}$ could not be established by solid state analysis. In contrast, ${ }^{7} \mathrm{Li}$ NMR spectroscopy in $\mathrm{C}_{6} \mathrm{D}_{6}$ (see ESI $\dagger$ ) identified three Li-containing species in solution: a minor signal at $\delta 1.65 \mathrm{ppm}$ which matched $\boldsymbol{i}-\mathbf{9 a}$, a dominant resonance at $\delta 0.91 \mathrm{ppm}$ corresponding to $9 \mathbf{a}$ and a shoulder at $\delta 0.94 \mathrm{ppm}$. Since $9 \mathbf{a}$ and $\boldsymbol{i}-\mathbf{9 a}$ contain equal amounts of $\mathrm{Cu}$ and $\mathrm{Li}$, it was anticipated that the unidentified species should be rich in $\mathrm{Cu}$ to ensure that the sample was $\mathrm{Cu}$-rich overall. Strong contenders include $\mathrm{TMP}_{3}$ $\mathrm{Cu}_{2} \mathrm{Li}$ and $\mathrm{TMP}_{4} \mathrm{Cu}_{3} \mathrm{Li}$ - since literature precedents exist for trimeric and tetrameric variants of $9 b^{36-38}$ and $9 c^{39,40}$

Lastly, the solution behaviour of co-crystalline $(\mathrm{DA})_{2} \mathrm{Cu}(\mathrm{Br})$ $\mathrm{Li}_{2}(\mathrm{TMEDA})_{2} \quad \mathbf{1 2 a} /(\mathrm{DA})_{2} \mathrm{Li}(\mathrm{Br}) \mathrm{Li}_{2}(\mathrm{TMEDA})_{2} \quad \mathbf{1 2 b}$ was probed in conjunction with that of pure $\mathbf{1 2 b}$. The data for pure $\mathbf{1 2 b}$ proves relatively straightforward. It suggests one species dominant in solution (alongside minimal reformation of DAH ${ }^{41}$ Fig. 9). Most clearly, ${ }^{7} \mathrm{Li}$ NMR spectroscopy reveals signals in the expected $1: 2$ ratio at $\delta 2.28$ and $1.26 \mathrm{ppm}$ (ESI, Fig. S11c $\dagger$ ). Moving to cocrystalline $\mathbf{1 2}$, peaks corresponding to $\mathbf{1 2 b}$ are added to by signals for 12a (ESI, Fig. S12a-f $f$ ). ${ }^{1} \mathrm{H}$ NMR spectroscopic data for multiple samples of $\mathbf{1 2}$ clearly show the levels of $\mathbf{1 2 a}$ and $\mathbf{1 2 b}$ to be variable (Fig. 9), pointing to the possibility of incorporating higher levels of $\mathrm{Cu}$ than evidenced by X-ray crystallography.

\section{Conclusions}

The recent development of thiocyanatocuprate reagents has been extended to yield cyanatocuprates. Copper-lithium exchange in this new field has been evidenced by the observation of co-crystalline products of the type (TMP $)_{2} \mathrm{M}(\mathrm{OCN}) \mathrm{Li}_{2}$ where $\mathrm{M}=\mathrm{Cu}, \mathrm{Li}$. An analysis of the geometry at $\mathrm{M}$ reinforces the view, recently expressed for $\mathrm{X}=\mathrm{CN}$, halide, and $\mathrm{SCN},{ }^{21,23}$ that in (amido) ${ }_{2} \mathrm{M}(\mathrm{X}) \mathrm{Li}_{2}$ systems $(\mathrm{X}=$ inorganic anion) $\mathrm{Cu}$ prefers a linear, dicoordiante geometry (viz. 8). This disinclination for higher order structure formation is emphasised when, for $\mathrm{M}=\mathrm{Li}$, a tendency for transannulation emerges and $\mathrm{M}$ becomes tricoordinate within the same structure-type (viz. 11). These data are reinforced by attempts to fabricate monomeric Lipshutz-type cuprates, with $\mathrm{Cu}$ linear in (DA) $2^{-}$ $\mathrm{Cu}(\mathrm{Br}) \mathrm{Li}_{2}(\mathrm{TMEDA})_{2}$ 12a and amidolithium-lithiocuprate adduct 13 and $\mathrm{Li}$ trigonal in $(\mathrm{DA})_{2}(\mathrm{Br}) \mathrm{Li}_{3}(\mathrm{TMEDA})_{2} \mathbf{1 2 b}$.

Solution studies have helped elucidate the complex chemistry on offer. In particular, insights into the behaviour of bulk $\mathbf{8}$ and also of $\mathbf{1 1}$ establish the in situ formation of Gilman cuprate 9a. We show that this can form directly or through the rearrangement of a newly observed species $(\boldsymbol{i}-9 \mathrm{a})$ that we propose to form kinetically from the combination of amidolithium $\mathbf{9 b}$ and amidocopper 9c. In the case of $\mathbf{1 2}$, results from crystallographic refinement could be combined with spectroscopic studies of 12b to distinguish copper-containing Lisphutz-type monomers from their lithium-only congeners. Work is being initiated to deconvolute the complex solution chemistry of $\mathbf{1 3}$ and to establish the synthetic portfolio of cyantocuprates. This is focusing on enhancing atom efficiency in directed ortho cupration ${ }^{19}$ and halopyridine ${ }^{21}$ derivatization by combining Gilman dimer $\mathbf{9} \mathbf{a}_{2}$ with substoichiometric LiOCN. The current work demonstrates, for the first time, the ability of an inorganic salt to combine with a dimeric Gilman cuprate to yield a Lipshutztype dimer. Taking this together with previous work establishing Lipshutz-type dimers as a source of reactive Gilman monomers ${ }^{19}$ alongside reformed lithium salt, we are now testing the non-stoichiometric deployment of LiOCN with a view to furthering recent interest in transferring main group polar organometallic chemistry to the catalytic regime. ${ }^{7 d, 42}$ 


\section{Experimental section}

\section{General synthetic and analytical details}

Reactions were carried out under dry nitrogen, using double manifold and glove-box methods. Solvents were distilled off sodium (toluene) or sodium-potassium amalgam (THF, hexane) immediately before use. 2,2,6,6-Tetramethylpiperidine (TMPH) was purchased from Alfa Aesar and stored over molecular sieves ( 4 A $)$. Other chemicals were used as received. $n \mathrm{BuLi}$ (1.6 $\mathrm{M}$ in hexanes) was purchased from Acros and used as received. For details of the syntheses of $\mathrm{Ba}(\mathrm{OCN})_{2} 6,{ }^{32} \mathrm{CuOCN} 7$ (ref. 32) and $\left(\mathrm{TMPH}_{2}\right) \mathrm{OCN} 10$ see the ESI. $\uparrow$ The syntheses of reference materials TMPLi $9 \mathbf{b}$ and TMPCu $9 \mathbf{c}$ were based on the literature $^{36,43}$ and details are provided in the ESI. $\dagger$ IR spectra were collected on a Perkin Elmer Spectrum One FT IR spectrometer. The abbreviations used are: $\mathrm{m}=$ medium, $\mathrm{s}=$ strong. NMR data were collected on a Bruker Avance III HD $500 \mathrm{MHz}$ Smart Probe FT NMR spectrometer $\left(500.200 \mathrm{MHz}\right.$ for ${ }^{1} \mathrm{H}$, 125.775 $\mathrm{MHz}$ for ${ }^{13} \mathrm{C}, 194.397$ for $\left.{ }^{7} \mathrm{Li}\right)$. Spectra were obtained at $25{ }^{\circ} \mathrm{C}$ using deuterated solvent stored over molecular sieves (3 $\AA$ ). For ${ }^{1} \mathrm{H}$ and ${ }^{13} \mathrm{C}$, chemical shifts are internally referenced to deuterated solvent and calculated relative to TMS. For ${ }^{7} \mathrm{Li}$, an external reference was used $\left(1 \mathrm{M} \mathrm{LiCl}\right.$ in $\left.\mathrm{D}_{2} \mathrm{O}\right)$. Chemical shifts are expressed in $\delta \mathrm{ppm}$. The following abbreviations are used: br $=$ broad, $\mathrm{m}=$ multiplet, $\mathrm{s}=$ singlet, $\mathrm{sh}=$ shoulder.

\section{Crystallographic details}

For details of data collections see Table 1. Crystals were transferred from the mother liquor to a drop of perfluoropolyether oil mounted upon a microscope slide under cold nitrogen gas. ${ }^{\mathbf{4 4}}$ Suitable crystals were attached to the goniometer head via a MicroLoop ${ }^{\mathrm{TM}}$, which was then centred on the diffractometer. Data were collected on a Bruker D8 Quest $(\mathrm{Cu}-\mathrm{K} \alpha, \lambda=1.54184$ $\AA$ ), each equipped with an Oxford Cryosystems low-temperature device $(T=180(2) \mathrm{K})$. Structures were solved using SHELXT, ${ }^{45}$ with refinement, based on $\mathrm{F}^{2}$, by full-matrix least squares. ${ }^{46}$ Non-hydrogen atoms were refined anisotropically (for disorder, standard restraints and constraints were employed as appropriate) and a riding model with idealized geometry was employed for the refinement of H-atoms. Crystals of 8a grew as two-component non-merohedral twins (see ESI $\dagger$ ). Data have been deposited with the Cambridge Crystallographic Data Centre as supplementary publications CCDC 1540281 (8), 1540280 (8a), 1540286 (9), 1540282 (11), 1540284 (12), 1540285 (12b) and 1540283 (13).

\section{Synthesis and characterization of $(\mathrm{TMP})_{2} \mathrm{Cu}_{0.1} \mathrm{Li}_{0.9}(\mathrm{OCN})$ $\mathbf{L i}_{2}$ (THF) 8}

To a stirred solution of TMPH $(0.34 \mathrm{~mL}, 2 \mathrm{mmol})$ and THF (0.08 $\mathrm{mL}, 1 \mathrm{mmol})$ in hexane $(4 \mathrm{~mL})$ was added $n \mathrm{BuLi}(1.25 \mathrm{~mL}, 1.6 \mathrm{M}$ in hexanes, $2 \mathrm{mmol}$ ) at $-78{ }^{\circ} \mathrm{C}$. The mixture was returned to room temperature to give a yellow solution. This was added to a suspension of CuOCN $(0.11 \mathrm{~g}, 1 \mathrm{mmol})$ in hexane $(1 \mathrm{~mL})$ at $-78{ }^{\circ} \mathrm{C}$. The mixture was returned to room temperature to give a pale yellow suspension. Filtration gave a yellow solution and storage at $-27{ }^{\circ} \mathrm{C}$ gave crystalline material from which a well- faceted, block-like crystal of (TMP) ${ }_{2} \mathrm{Cu}_{0.1} \mathrm{Li}_{0.9}(\mathrm{OCN}) \mathrm{Li}_{2}(\mathrm{THF})$ was selected for X-ray diffraction. The following characterization refers to the bulk crystalline product. Yield $54 \mathrm{mg}$, melting point dec. from $125^{\circ} \mathrm{C}$. Selected IR spectroscopy (nujol) $\bar{\nu} 2208$ (s, CN), 1340 (m, CO), 1229 (m, CO) $\mathrm{cm}^{-1} .{ }^{1} \mathrm{H}$ NMR spectroscopy (500 $\left.\mathrm{MHz}, \mathrm{C}_{6} \mathrm{D}_{6}\right) \delta 3.56$ (m, 8H, THF), 2.17-1.77 (br, 8H, TMP-4), 1.75 (s, 6H, TMP-Me), 1.74-1.60 (br, m, 12H, TMP-3,5, TMP-Me), 1.57 (s, 12H, TMP-Me), 1.56-1.41 (br, m, 12H, TMP-3,5, TMP-4, TMPMe), 1.39 (s, 6H, TMP-Me), 1.36 (m, 8H, THF), 1.34-1.13 (br, 12H, TMP-3,5), 1.12-1.07 (m, 4H, TMP-3,5), 1.06 (s, 2H, TMPH-Me). ${ }^{13} \mathrm{C}$ NMR (125 MHz, $\mathrm{C}_{6} \mathrm{D}_{6}$ ) $\delta 64.8$ (THF), 56.9 (TMP-2,6 i-9a), 54.2 (TMP-2,6 $i$-9a/TMP-2,6 9a), 53.4 (TMP-2,6 8), 52.0 (TMP-2, 6 i9a), 51.6 (TMP-2,6 11), 49.2 (TMPH-2,6), 42.6 (TMP-3,5 i-9a), 42.5 (TMP-3,5 i-9a), 42.4 (TMP-3,5 8), 42.1 (TMP-3,5 i-9a/TMP-3,5 9a), 41.9 (TMP-3,5 11), 40.5 (TMP-Me 8), 40.2 (TMP-Me 9a), 39.7 (TMP-Me i-9a), 38.1 (TMPH-3,5), 37.5 (br, TMP-Me 11), 37.0 (TMP-Me i-9a), 36.8 (TMP-Me i-9a), 35.7 (TMP-Me 8), 34.5 (TMPMe 9a), 34.2 (TMP-Me i-9a), 33.5 (br, TMP-Me 11), 31.6 (TMPHMe), 25.1 (THF), 20.1 (TMP-4 11), 19.6 (TMP-4 i-9a), 19.2 (TMP4 i-9a/TMP-4 9a), 19.1 (TMP-4 8), 19.1 (TMP-4 i-9a), 18.4 (TMPH-4). ${ }^{7} \mathrm{Li}$ NMR (194 MHz, $\mathrm{C}_{6} \mathrm{D}_{6}$ ) $\delta 2.17$ (br, s, 1Li, 9b), 1.64 (s, 1.5Li, i-9a), 1.39 (br, s, 2Li, 11), 0.90 (s, 0.5Li, 9a), 0.48 (s, 0.5Li, 8).

\section{Synthesis and characterization of (TMP) $)_{2} \mathrm{Cu}(\mathrm{OCN}) \mathrm{Li}_{2}(\mathrm{THF}) 8 \mathrm{a}$}

To a stirred solution of TMPH $(0.68 \mathrm{~mL}, 4 \mathrm{mmol})$ in hexane (2 $\mathrm{mL})$ and toluene $(2 \mathrm{~mL})$ was added $n$ BuLi $(2.5 \mathrm{~mL}, 1.6 \mathrm{M}$ in hexanes, $4 \mathrm{mmol}$ ) at $-78{ }^{\circ} \mathrm{C}$. The solution was warmed to room temperature and transferred to a suspension of CuSCN $(0.243 \mathrm{~g}$, $2 \mathrm{mmol})$ in hexane $(2 \mathrm{~mL})$ and toluene $(2 \mathrm{~mL})$. The suspension was warmed to room temperature then heated to reflux whereupon a grey discolouration was observed. To remove LiSCN, this mixture was filtered whilst hot onto LiOCN $(0.10 \mathrm{~g}, 2$ $\mathrm{mmol}$ ) and the solvent was removed in vacuo. THF $(6 \mathrm{~mL})$ was added and the suspension was stirred at room temperature for 30 minutes, during which time partial dissolution of the LiOCN occurred. The THF was removed in vacuo to give a sticky solid, which dissolved when hexane $(6 \mathrm{~mL})$ was added. The solution was filtered and the filtrate stored at $-27^{\circ} \mathrm{C}$ for 1 week during which time 8a deposited as radiating fans of crystals. Yield $310 \mathrm{mg}$ (33\% wrt. CuSCN), melting point $192-194{ }^{\circ} \mathrm{C}$. Elemental analysis $\mathrm{C}_{24} \mathrm{H}_{48} \mathrm{CuLi}_{2} \mathrm{~N}_{3} \mathrm{O}_{2}$, requires (\%) C, 58.52; $\mathrm{H}, 9.40 ; \mathrm{N}$, 8.90. Found (\%) C, 58.06; H, 9.38; N, 9.01. Selected IR spectroscopy (nujol) $\bar{\nu} 2241$ (s, CN), 2208 (s, CN), 1340 (m, CO), 1228 $(\mathrm{m}, \mathrm{CO}) \mathrm{cm}^{-1} .{ }^{1} \mathrm{H}$ NMR spectroscopy $\left(500 \mathrm{MHz}, \mathrm{C}_{6} \mathrm{D}_{6}\right) \delta 3.57$ (br, $\mathrm{m}, 4 \mathrm{H}, \mathrm{THF}$ ), 1.89-1.76 (br, m, 2H, TMP-4), 1.67-1.61 (m, 4H, TMP-3,5), 1.60 (s, 12H, TMP-Me), 1.59-157 (m, 2H, TMP-4), 1.56 (s, 12H, TMP-Me), 1.41 (br, m, 4H, THF), 1.09 (m, 4H, TMP-3,5), 1.06 (s, 1.3H, TMPH-Me). ${ }^{13} \mathrm{C}$ NMR spectroscopy $(125 \mathrm{MHz}$, $\mathrm{C}_{6} \mathrm{D}_{6}$ ) $\delta 67.4$ (br, THF), 54.2 (TMP-2,6), 49.2 (TMPH-2,6), 42.1 (TMP-3,5), 40.1 (TMP-Me), 38.2 (TMPH-3,5), 34.5 (TMP-Ме), 31.6 (TMPH-Me), 25.3 (br, THF), 19.2 (TMP-4), 18.4 (ТМРH-4). ${ }^{7} \mathrm{Li}$ NMR spectroscopy $\left(194 \mathrm{MHz}, \mathrm{C}_{6} \mathrm{D}_{6}\right) \delta 0.90$.

\section{Synthesis and characterization of (TMP) $)_{2} \mathrm{Cu}_{1.35} \mathrm{Li}_{0.65} 9$}

To a stirred solution of TMPH $(0.34 \mathrm{~mL}, 2 \mathrm{mmol})$ and THF (2 $\mathrm{mL}$ ) was added $n \mathrm{BuLi}(1.25 \mathrm{~mL}, 1.6 \mathrm{M}$ in hexanes, $2 \mathrm{mmol})$ at 


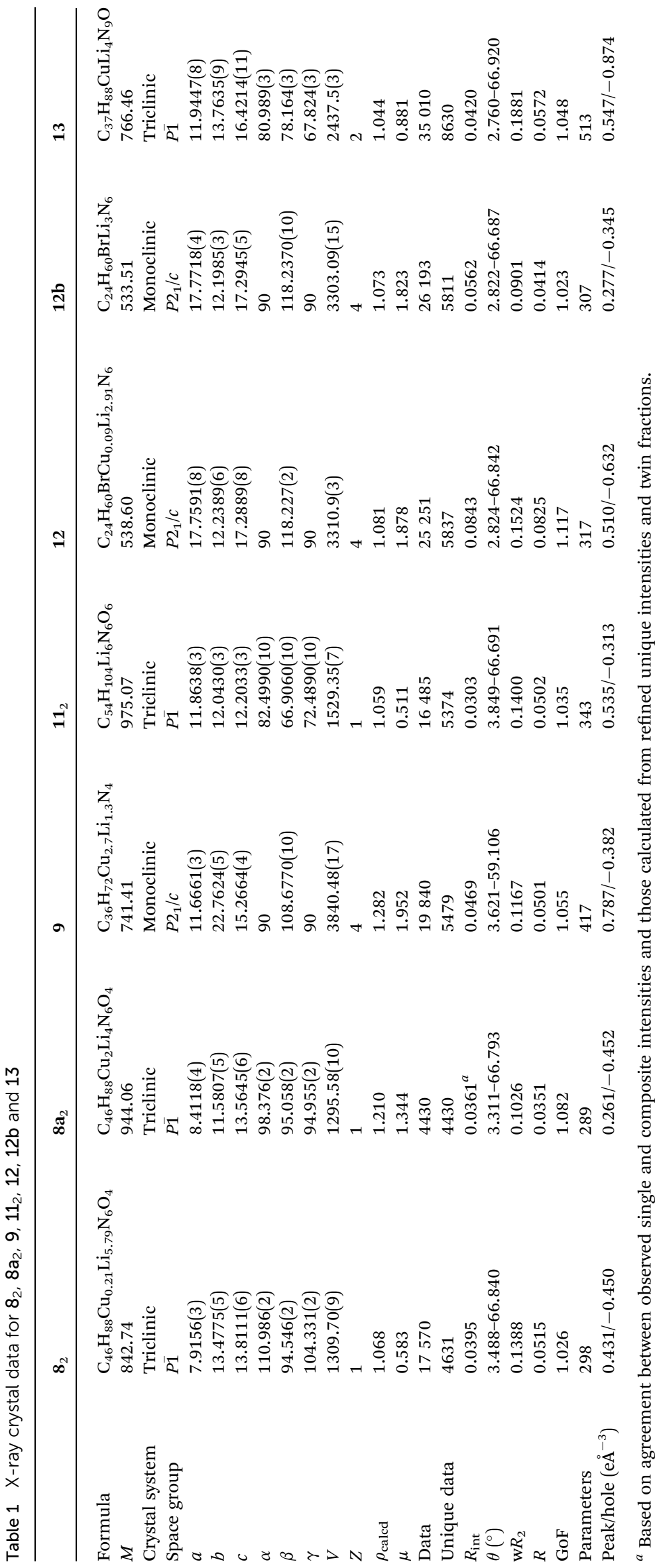


$-78^{\circ} \mathrm{C}$. The mixture was left to reach room temperature. The resulting yellow solution was transferred to a suspension of CuOCN $(0.11 \mathrm{~g}, 1 \mathrm{mmol})$ in THF $(1 \mathrm{~mL})$ at $-78{ }^{\circ} \mathrm{C}$. The mixture was returned to room temperature to give a pale yellow suspension. The solvent was removed and the resulting yellow solid dissolved in hexane $(4 \mathrm{~mL})$. Filtration gave a yellow solution that was stored at $-27{ }^{\circ} \mathrm{C}$ to give a crystalline aggregate which analysed as (TMP) ${ }_{2} \mathrm{Cu}_{1.35} \mathrm{Li}_{0.65}$ by X-ray diffraction. Yield $65 \mathrm{mg} .{ }^{1} \mathrm{H}$ NMR spectroscopy (500 MHz, $\left.298 \mathrm{~K}, \mathrm{C}_{6} \mathrm{D}_{6}\right) \delta 1.89-$ 1.80 (m, 4H, TMP-4), 1.79 (s, 6H, TMP-Me), 1.76 (s, 8H, TMPMe), 1.73 (s, br, 6H, TMP-Me), 1.72-1.69 (br, m, 4H, TMP-4), 1.68-1.61 (m, 4H, TMP-3,5), 1.59 (s, 12H, TMP-Ме; ТМР-Ме 9a), 1.57 (s, 10H, TMP-Me; TMP-3,5; TMP-4), 1.56 (s, 12H, TMP-Me 9a), 1.10 (m, 6H, TMP-3,5), 1.06 (s, 1H, TMPH-Me) ${ }^{13} \mathrm{C}$ NMR spectroscopy (125 MHz, $298 \mathrm{~K}, \mathrm{C}_{6} \mathrm{D}_{6}$ ) $\delta 56.9$ (TMP-2,6), 54.2 (TMP-2,6), 54.2 (TMP-2,6 9a), 49.2 (ТMPH-2,6), 42.6 (TMP-3,5), 42.5 (TMP-3,5), 42.1 (TMP-3,5 9a), 42.1 (TMP-3,5), 40.1 (TMP-Me 9a), 39.7 (TMP-Me), 38.2 (TMPH-3,5), 37.6 (br, TMP-Me), 37.2 (br, TMP-Me), 36.6 (br, TMP-Me), 34.8 (TMP-Me), 34.5 (TMP-Me 9a), 31.6 (TMPH-Me), 19.3 (TMP-4), 19.2 (TMP-4 9a), 19.2 (TMP-4), 18.4 (TMPH-4). ${ }^{7} \mathrm{Li}$ NMR spectroscopy (194 $\left.\mathrm{MHz}, 298 \mathrm{~K}, \mathrm{C}_{6} \mathrm{D}_{6}\right) \delta 1.65$ (s, 0.16Li), 0.94 (sh, 0.8Li), 0.91 (s, 1.0Li, 9a).

\section{Synthesis and characterization of $(\mathrm{TMP})_{2}(\mathrm{OCN}) \mathrm{Li}_{3}(\mathrm{THF})_{2} 11$}

Method (a). A suspension of $\left(\mathrm{TMPH}_{2}\right) \mathrm{OCN} 10(0.09 \mathrm{~g}, 0.5$ $\mathrm{mmol})$ in THF $(2 \mathrm{~mL})$ was treated with $\mathrm{TMPH}(0.08 \mathrm{~mL}, 0.5$ mmol). $n$ BuLi (0.95 mL, $1.5 \mathrm{mmol}$ ) was added dropwise at $-78{ }^{\circ} \mathrm{C}$ and the resulting suspension was left to warm to room temperature, whereupon it dissolved. The solvent was removed in vacuo and replaced with hexane $(3 \mathrm{~mL})$. The colourless solution was filtered, with storage of the filtrate at $-27{ }^{\circ} \mathrm{C}$ for 1 day giving colourless crystals. Yield $65 \mathrm{mg}$ (27\% wrt. NCO), melting point $90-92{ }^{\circ} \mathrm{C}$. Selected IR spectroscopy (nujol) $\bar{\nu} 2207$ (s, CN), 1352 (s, CO), 1226 (s, CO) $\mathrm{cm}^{-1} .{ }^{1} \mathrm{H}$ NMR spectroscopy $\left(500 \mathrm{MHz}, \mathrm{C}_{6} \mathrm{D}_{6}\right) \delta 3.56(\mathrm{~m}, 8 \mathrm{H}, \mathrm{THF}), 2.27-1.37$ (br, m, 30H, TMP-3,4,5,Me), 1.35 (s, 6H, TMP-Me), 1.34 (m, 8H, THF), 1.06 (s, 3.2H, TMPH-Me), 0.31 (br, s, 0.31H, TMPH-NH). ${ }^{13} \mathrm{C}$ NMR (126 MHz, $\mathrm{C}_{6} \mathrm{D}_{6}$ ) $\delta 67.8$ (THF), 52.0 (TMP-2,6 9b), 51.7 (TMP-2,6 11), 49.2 (ТMPH-2,6), 42.4 (TMP-3,5 9b), 41.9 (TMP-3,5 11), 38.2 (TMPH-3,5), 37.5 (br, TMP-Me 11), 36.5 (TMP-Me 9b), 33.5 (br, TMP-Me 11), 31.6 (TMPH-Me), 25.0 (THF), 20.2 (TMP-4 11), 18.4 (TMPH-4). ${ }^{7} \mathrm{Li}$ NMR (194 MHz, $\mathrm{C}_{6} \mathrm{D}_{6}$ ) $\delta 2.21$ (s, br, 1Li, 9b), 1.48 (s, br, 2Li, 11), -1.54 (s, 0.2Li, unidentified).

Method (b). TMPH $(0.34 \mathrm{~mL}, 2 \mathrm{mmol})$ in THF $(2 \mathrm{~mL})$ was treated with $n \mathrm{BuLi}(1.25 \mathrm{~mL}, 1.6 \mathrm{M}$ in hexanes, $2 \mathrm{mmol})$ at $-78{ }^{\circ} \mathrm{C}$. The pale yellow solution was returned to room temperature whereupon it was transferred to a suspension of LiOCN $(0.05 \mathrm{~g}, 1 \mathrm{mmol})$ in THF at $-78{ }^{\circ} \mathrm{C}$. The mixture warmed to room temperature and was stirred for $c a .15$ minutes, during which time the LiOCN was observed to dissolve. The solvent was removed in vacuo, leaving a sticky white solid which dissolved upon the addition of hexane $(6 \mathrm{~mL})$ with gentle warming. The solution was filtered and the filtrate stored at $-27^{\circ} \mathrm{C}$ for $24 \mathrm{~h}$ hours to give colourless crystals. Yield $75 \mathrm{mg}$ (15\% wrt LiOCN). Elemental analysis, $\mathrm{C}_{27} \mathrm{H}_{52} \mathrm{Li}_{3} \mathrm{~N}_{3} \mathrm{O}_{3}$ requires (\%) $\mathrm{C} 66.52, \mathrm{H}$
10.75, N 8.62; found (\%) C, 66.08; H, 10.76; N, 8.83. ${ }^{1} \mathrm{H}$ NMR (500 MHz, $\mathrm{C}_{6} \mathrm{D}_{6}$ ): $\delta 3.56$ (m, 8H, THF), 2.31-1.38 (br, 30H, TMP), 1.35 (m, 8H, THF), 1.32-1.12 (br, 6H, TMP), 1.06 (s, 1H, TMPH). ${ }^{13} \mathrm{C}$ NMR (125 MHz, $\mathrm{C}_{6} \mathrm{D}_{6}$ ): $\delta 67.9$ (THF), 51.6 (TMP-2,6), 49.2 (TMPH-2,6), 41.9 (TMP-3,5), 38.2 (ТMPH-3,5), 37.1 (br, TMPMe), 33.5 (br, TMP-Me), 31.6 (TMPH-Me), 25.0 (THF), 20.1 (TMP-4), 18.4 (TMPH-4). ${ }^{7} \mathrm{Li}$ NMR (194 MHz, $\left.\mathrm{C}_{6} \mathrm{D}_{6}\right): \delta 1.38$ (s, br).

\section{Synthesis and characterization of $(\mathrm{DA})_{2} \mathrm{Cu}_{0.09} \mathrm{Li}_{0.91}(\mathrm{Br})$ Li $_{2}(\text { TMEDA) })_{2} 12$}

$n \operatorname{BuLi}(2.5 \mathrm{~mL}, 1.6 \mathrm{M}$ in hexanes, $4 \mathrm{mmol})$ was added to a stirred solution of DAH $(0.56 \mathrm{~mL}, 4 \mathrm{mmol})$ and TMEDA $(0.6 \mathrm{~mL}, 4$ $\mathrm{mmol})$ in hexane $(4 \mathrm{~mL})$ at $-78{ }^{\circ} \mathrm{C}$. The resulting solution was returned to room temperature to give a yellow solution that was transferred to $\mathrm{a}-78^{\circ} \mathrm{C}$ suspension of $\mathrm{CuBr}(0.28 \mathrm{~g}, 2 \mathrm{mmol})$ in hexane $(2 \mathrm{~mL})$. The mixture was returned to room temperature to give a brown suspension. Filtration gave a pale yellow solution. Storage of this at $-27{ }^{\circ} \mathrm{C}$ for 24 hours gave colourless blocks of cocrystalline Lipshutz-type $(\mathrm{DA})_{2} \mathrm{Cu}(\mathrm{Br}) \mathrm{Li}_{2}(\mathrm{TMEDA})_{2}$ 12b and $(\mathrm{DA})_{2}(\mathrm{Br}) \mathrm{Li}_{3}(\mathrm{TMEDA})_{2}$ 12a. Yield $350 \mathrm{mg}$.

Representative sample (1). ${ }^{1} \mathrm{H}$ NMR spectroscopy (500 MHz, $\left.\mathrm{C}_{6} \mathrm{D}_{6}\right) \delta 3.76$ (sh, br, 0.36H, DA-CH, 12a), 3.67 (s, br, 3.15H, DA$\mathrm{CH}, 12 \mathrm{~b}$ ), 3.25 (septet, ${ }^{3} \mathrm{H}_{\mathrm{HH}}=6 \mathrm{~Hz}, 0.02 \mathrm{H}, \mathrm{DA}-\mathrm{CH}, 12 \mathrm{a}$ ), 3.16 (septet, $\left.{ }^{3} J_{\mathrm{HH}}=6 \mathrm{~Hz}, 0.08 \mathrm{H}, \mathrm{DA}-\mathrm{CH}, 12 \mathrm{a}\right), 3.10$ (septet, ${ }^{3} J_{\mathrm{HH}}=$ $6 \mathrm{~Hz}, 0.28 \mathrm{H}, \mathrm{DA}-\mathrm{CH}, 12 \mathrm{a}$ ), 2.78 (octet, ${ }^{3} J_{\mathrm{HH}}=6 \mathrm{~Hz}, 0.4 \mathrm{H}, \mathrm{DAH}-$ $\mathrm{CH}$ ), 2.13 (s, 24H, TMEDA-Me), 1.99 (s, 8H, TMEDA-CH ${ }_{2}$ ), 1.631.20 (br, m, 24H, 12a + 12b), $0.95\left(\mathrm{~d},{ }^{3} \mathrm{~J}_{\mathrm{HH}}=6 \mathrm{~Hz}, 2 \mathrm{H}, \mathrm{DAH}-\mathrm{Me}\right)$. ${ }^{13} \mathrm{C}$ NMR (126 MHz, $\mathrm{C}_{6} \mathrm{D}_{6}$ ) $\delta 57.0\left(\mathrm{TMEDA}-\mathrm{CH}_{2}\right.$ ), 50.1 (DA-CH, 12a), 48.8 (DA-CH, 12b), 46.5 (TMEDA- $\mathrm{CH}_{3}$ ), 44.9 (DAH-CH), 28.2, 27.0 (DA-Me, 12a), 26.2 (br, DA-Me, 12b), 23.2 (DAH-Me). ${ }^{7} \mathrm{Li}$ NMR (194 MHz, $\mathrm{C}_{6} \mathrm{D}_{6}$ ) $\delta 2.34$ (s, 1Li, (DA) $\left.2 \mathrm{Li}, 12 \mathrm{~b}\right), 1.58$ (s, 0.4Li, Li(TMEDA), 12a), 1.18 (s, 2Li, Li(TMEDA), 12b).

Representative sample (2). ${ }^{1} \mathrm{H}$ NMR spectroscopy (500 MHz, $\mathrm{C}_{6} \mathrm{D}_{6}$ ) $\delta 3.76$ (sh, br, 0.11H, DA-CH, 12a), 3.67 (s, br, 1.90H, DA$\mathrm{CH}, 12 \mathrm{~b}$ ), 3.25 (septet, ${ }^{3} \mathrm{JHH}_{\mathrm{HH}}=6 \mathrm{~Hz}, 0.02 \mathrm{H}, \mathrm{DA}-\mathrm{CH}, 12 \mathrm{a}$ ), 3.16 (septet, $\left.{ }^{3} J_{\mathrm{HH}}=6 \mathrm{~Hz}, 0.64 \mathrm{H}, \mathrm{DA}-\mathrm{CH}, 12 \mathrm{a}\right), 3.11$ (septet, ${ }^{3} J_{\mathrm{HH}}=$ $6 \mathrm{~Hz}, 1.00 \mathrm{H}, \mathrm{DA}-\mathrm{CH}, 12 \mathrm{a}$ ), 2.78 (octet, ${ }^{3} J_{\mathrm{HH}}=6 \mathrm{~Hz}, 0.16 \mathrm{H}, \mathrm{DAH}-$ $\mathrm{CH}$ ), 2.14 (s, 24H, TMEDA-Me), 2.02 (s, 8H, TMEDA- $\mathrm{CH}_{2}$ ), 1.601.31(br, m, 20H, DA-Me, 12a + 12b), $1.25\left(\mathrm{~d},{ }^{3} J_{\mathrm{HH}}=6 \mathrm{~Hz}, 2 \mathrm{H}\right.$, 12a), $1.22\left(\mathrm{~d},{ }^{3} J_{\mathrm{HH}}=6 \mathrm{~Hz}, 2 \mathrm{H}, 12 \mathrm{a}\right), 0.94\left(\mathrm{~d},{ }^{3} J_{\mathrm{HH}}=6 \mathrm{~Hz}, 1 \mathrm{H}\right.$, DAH-Me). ${ }^{13} \mathrm{C}$ NMR (125 MHz, $\left.\mathrm{C}_{6} \mathrm{D}_{6}\right) \delta 57.0$ (TMEDA- $\mathrm{CH}_{2}$ ), 50.9 (DA-CH, 12a), 50.4 (DA-CH, 12a), 50.1 (DA-CH, 12a), 48.8 (DA$\mathrm{CH}, 12 \mathrm{~b}$ ), 46.3 (TMEDA-Me), 44.8 (DAH-CH), 28.4 (DA-Me, 12a), 28.2 (DA-Me, 12a), 27.6 (DA-Me, 12a), 27.5 (DA-Me, 12a), 27.0 (DA-Me, 12a), 26.9 (DA-Me, 12a), 26.1 (br, DA-Me, 12b), 23.4 (DAH-Me). ${ }^{7} \mathrm{Li}$ NMR (194 MHz, $\left.\mathrm{C}_{6} \mathrm{D}_{6}\right) \delta 2.37$ (s, 1.0Li, 12b), 1.63 (s, 1.2Li, 12a), 1.59 (s, 1.0Li, 12a), 1.17 (s, 2Li, 12b).

\section{Synthesis and characterization of $(\mathrm{DA})_{2}(\mathrm{Br}) \mathrm{Li}_{3}(\mathrm{TMEDA})_{2} 12 \mathrm{~b}$}

To a suspension of $\mathrm{DAH} \cdot \mathrm{HBr}(0.18 \mathrm{~g}, 1 \mathrm{mmol})$ in hexane $(6 \mathrm{~mL})$ was added DAH $(0.14 \mathrm{~mL}, 1 \mathrm{mmol})$ and TMEDA $(0.30 \mathrm{~mL}, 2$ mmol). The mixture was cooled to $-78{ }^{\circ} \mathrm{C}$, treated with $n \mathrm{BuLi}$ (1.9 $\mathrm{mL}, 1.6 \mathrm{M}$ in hexanes, $3 \mathrm{mmol}$ ) and returned to room temperature to give a pale yellow solution. The solution was filtered, concentrated (to $\mathrm{ca} .4 \mathrm{~mL}$ ) and stored at $-27^{\circ} \mathrm{C}$ for 1 day after which colourless block-like crystals of $\mathbf{1 2 b}$ were 
deposited. Yield $320 \mathrm{mg}$ ( $60 \%$ wrt. Br), melting point $76-78{ }^{\circ} \mathrm{C}$. Elemental analysis, $\mathrm{C}_{24} \mathrm{H}_{60} \mathrm{BrLi}_{3} \mathrm{~N}_{6}$ requires (\%) C $54.03, \mathrm{H}$ 11.34, N 15.75; found (\%) C 54.09, H 11.66, N 15.58. ${ }^{1} \mathrm{H}$ NMR spectroscopy (500 MHz, $\left.\mathrm{C}_{6} \mathrm{D}_{6}\right) \delta 3.66$ (s, br, 2H, DA-CH), 2.79 (octet, $\left.{ }^{3} J_{\mathrm{HH}}=6 \mathrm{~Hz}, 0.06 \mathrm{H}, \mathrm{DAH}-\mathrm{CH}\right), 2.13$ (s, 24H, TMEDA-Me), 1.96 (s, 8H, TMEDA- $\mathrm{CH}_{2}$ ), 1.41 (s, br, 24H, DA-Me), 0.95 (d, ${ }^{3} \mathrm{JHH}_{\mathrm{HH}}$ $=6 \mathrm{~Hz}, 1.35 \mathrm{H}, \mathrm{DAH}-\mathrm{Me}) .{ }^{13} \mathrm{C} \mathrm{NMR}\left(126 \mathrm{MHz}, \mathrm{C}_{6} \mathrm{D}_{6}\right) \delta 56.9$ (TMEDA-CH ${ }_{2}$ ), 48.8 (DA-CH), 46.5 (TMEDA-CH ${ }_{3}$ ), 44.9 (DAH$\mathrm{CH}), 26.2$ (DA-Me), 23.2 (DAH-Me). ${ }^{7} \mathrm{Li} \mathrm{NMR}\left(194 \mathrm{MHz}, \mathrm{C}_{6} \mathrm{D}_{6}\right.$ ) $\delta 2.28$ (s, br, 1Li, (DA) $\left.{ }_{2} \mathrm{Li}\right), 1.26$ (s, 2Li, Li(TMEDA)).

\section{Synthesis and characterization of $(\mathrm{DA})_{4} \mathrm{Cu}(\mathrm{OCN}) \mathrm{Li}_{4}(\mathrm{TMEDA})_{2}$} 13

$n$ BuLi (1.25 mL, 1.6 $\mathrm{M}$ in hexanes, $2 \mathrm{mmol}$ ) was added to a stirred solution of DAH $(0.28 \mathrm{~mL}, 2 \mathrm{mmol})$ and TMEDA $(0.3 \mathrm{~mL}, 2$ $\mathrm{mmol})$ in hexane $(4 \mathrm{~mL})$ at $-78{ }^{\circ} \mathrm{C}$. The resulting solution was returned to room temperature to give a yellow solution that was transferred to a suspension of CuOCN $(0.11 \mathrm{~g}, 1 \mathrm{mmol})$ in hexane $(1 \mathrm{~mL})$ at $-78^{\circ} \mathrm{C}$. The mixture was returned to room temperature to give a grey suspension, which was filtered to give a pale yellow solution. Storage at $+5{ }^{\circ} \mathrm{C}$ for 24 hours gave white needle-like crystals of 13 . Yield $0.11 \mathrm{~g}(14 \%$ wrt. CuOCN), melting point dec. ca. $95{ }^{\circ} \mathrm{C}$. Elemental analysis, $\mathrm{C}_{37} \mathrm{H}_{88} \mathrm{CuLi}_{4} \mathrm{~N}_{9} \mathrm{O}$ requires (\%) C, 57.98; H, 11.57; N, 16.45. Found: C, 57.77; H, 11.68; N, 16.76. Selected IR spectroscopy (nujol) $\bar{\nu} 2207$ (s, CN), 1353 (m, CO), 1293 (m, CO) $\mathrm{cm}^{-1}$. ${ }^{1} \mathrm{H}$ NMR spectroscopy (500 $\mathrm{MHz}, \mathrm{C}_{6} \mathrm{D}_{6}$ ) ઈ 3.88-3.40 (br, m, 6.2H, DA-CH), 3.28 (br, m, 0.53H, DA-CH), $3.14(\mathrm{~m}, 0.15 \mathrm{H}, \mathrm{DA}-\mathrm{CH}), 3.11$ (septet, ${ }^{3} J_{\mathrm{HH}}=6 \mathrm{~Hz}, 1.12 \mathrm{H}, \mathrm{DA}-$ $\mathrm{CH}$ ), 2.78 (octet, $\left.{ }^{3} J_{\mathrm{HH}}=6 \mathrm{~Hz}, 0.14 \mathrm{H}, \mathrm{DAH}-\mathrm{CH}\right), 2.01(\mathrm{~s}, 24 \mathrm{H}$, TMEDA-Me), 1.94 (s, 8H, TMEDA- $\mathrm{CH}_{2}$ ), 1.71-1.38 (br, m, 22H, DA-Me), 1.37 (d, $\left.{ }^{3} J_{\mathrm{HH}}=6 \mathrm{~Hz}, 3 \mathrm{H}, \mathrm{DA}-\mathrm{Me}\right), 1.35-1.25(\mathrm{br}, \mathrm{m}, 16 \mathrm{H}$, DA-Me), 1.23 (d, $\left.{ }^{3} \mathrm{H}_{\mathrm{HH}}=6 \mathrm{~Hz}, 3 \mathrm{H}, \mathrm{DA}-\mathrm{Me}\right), 1.22-1.14(\mathrm{br}, \mathrm{m}, 4 \mathrm{H}$, DA-Me), 0.94 (d, $\left.{ }^{3} J_{\mathrm{HH}}=6 \mathrm{~Hz}, 0.8 \mathrm{H}, \mathrm{DAH}-\mathrm{Me}\right) .{ }^{13} \mathrm{C}$ NMR (125 $\mathrm{MHz}, \mathrm{C}_{6} \mathrm{D}_{6}$ ) $\delta 57.3$ (TMEDA-CH${ }_{2}$ ), 50.1 (DA-CH), 49.8 (DA-CH), 49.6 (DA-CH), 49.2 (DA-CH), 48.6 (DA-CH), 48.3 (DA-CH), 45.9 (TMEDA-Me), 44.9 (DAH-CH), 44.8 (DAH-CH), 28.2 (DA-Me), 27.8 (DA-Me), 27.7 (DA-Me), 27.0 (DA-Me), 26.0 (DA-Me), 25.8 (DA-Me), 25.2 (DA-Me), 25.1 (DA-Me), 23.2 (DAH-Me), 23.1 (DAH-Me). ${ }^{7} \mathrm{Li}$ NMR (194 MHz, $\left.\mathrm{C}_{6} \mathrm{D}_{6}\right) \delta 2.34$ (br, s, 0.78Li), 2.14 (sh, 0.22Li), 1.58 (s, 0.94Li), 0.84 (s, 0.40Li), 0.37 (s, 1.66Li).

\section{Acknowledgements}

This work was supported by the U.K. EPSRC through grants EP/ J500380/1 and EP/K039520/1. Thanks go also to Dr Andrew Bond (University of Cambridge) for help with crystallographic analysis. Detailed supporting data for this paper are available at the University of Cambridge data repository (see https://doi.org/ 10.17863/CAM.9469).

\section{References}

1 Y. Kondo, M. Shilai, M. Uchiyama and T. Sakamoto, J. Am. Chem. Soc., 1999, 121, 3539-3540.

2 (a) R. E. Mulvey, Acc. Chem. Res., 2009, 42, 743-755; (b) R. E. Mulvey, Dalton Trans., 2013, 42, 6676-6693.
3 (a) R. E. Mulvey, V. L. Blair, W. Clegg, A. R. Kennedy, J. Klett and L. Russo, Nat. Chem., 2010, 2, 588-591; (b) A. J. MartínezMartínez, A. R. Kennedy, R. E. Mulvey and C. T. O'Hara, Science, 2014, 346, 834-837.

4 (a) M. Uchiyama, H. Naka, Y. Matsumoto and T. Ohwada, J. Am. Chem. Soc., 2004, 126, 10526-10527; (b) F. Mongin and M. Uchiyama, Curr. Org. Chem., 2011, 15, 2340-2361; (c) A. Harrison-Marchand and F. Mongin, Chem. Rev., 2013, 113, 7470-7562; (d) F. Mongin and A. Harrison-Marchand, Chem. Rev., 2013, 113, 7727.

5 (a) M. Uchiyama, T. Miyoshi, Y. Kajihara, T. Sakamoto, Y. Otani, T. Ohwada and Y. Kondo, J. Am. Chem. Soc., 2002, 124, 8514-8515; (b) M. Uchiyama, Y. Matsumoto, D. Nobuto, T. Furuyama, K. Yamaguchi and K. Morokuma, J. Am. Chem. Soc., 2006, 128, 8748-8750; (c) R. E. Mulvey, F. Mongin, M. Uchiyama and Y. Kondo, Angew. Chem., Int. Ed., 2007, 46, 3802-3824; (d) F. García, M. McPartlin, J. V. Morey, D. Nobuto, Y. Kondo, H. Naka, M. Uchiyama and A. E. H. Wheatley, Eur. J. Org. Chem., 2008, 644-647; (e) B. Haag, M. Mosrin, H. Ila, V. Malakhov and P. Knochel, Angew. Chem., Int. Ed., 2011, 50, 9794-9824.

6 R. P. Davies, Coord. Chem. Rev., 2011, 255, 1226-1251.

7 e.g. (a) J. Garcia-Álvarez, A. R. Kennedy, J. Klett and R. E. Mulvey, Angew. Chem., Int. Ed., 2007, 46, 1105-1109; (b) J. García-Álvarez, E. Hevia, A. R. Kennedy, J. Klett and R. E. Mulvey, Chem. Commun., 2007, 2402-2404; (c) R. P. Davies, S. Hornauer and P. B. Hitchcock, Angew. Chem., Int. Ed., 2007, 46, 5191-5194; (d) Y. Kondo, J. V. Morey, J. M. Morgan, P. R. Raithby, D. Nobuto, M. Uchiyama and A. E. H. Wheatley, J. Am. Chem. Soc., 2007, 129, 12734-12738; (e) H. Naka, J. V. Morey, J. Haywood, D. J. Eisler, M. McPartlin, F. García, H. Kudo, Y. Kondo, M. Uchiyama and A. E. H. Wheatley, J. Am. Chem. Soc., 2008, 130, 16193-16200; ( $f$ ) W. Clegg, J. GarciaÁlvarez, P. Garcia-Álvarez, D. V. Graham, R. W. Harrington, E. Hevia, A. R. Kennedy, R. E. Mulvey and L. Russo, Organometallics, 2008, 27, 2654-2663; (g) A. R. Kennedy, J. Klett, R. E. Mulvey and D. S. Wright, Science, 2009, 326, 706-708; (h) R. Bomparola, R. P. Davies, T. Gray and A. J. P. White, Organometallics, 2009, 28, 4632-4635.

8 D. R. Armstrong, E. Crosbie, E. Hevia, R. E. Mulvey, D. L. Ramsay and S. D. Robertson, Chem. Sci., 2014, 5, 3031-3045.

9 S. Sung, D. C. Braddock, A. Armstrong, C. Brennan, D. Sale, A. J. P. White and R. P. Davies, Chem.-Eur. J., 2015, 21, 71797192.

10 (a) H. Gilman, R. Jones and L. Woods, J. Org. Chem., 1952, 17, 1630; (b) H. House, W. Respess and G. Whitesides, J. Org. Chem., 1966, 31, 3128-3141.

11 (a) P. Reiss and D. Fenske, Z. Anorg. Allg. Chem., 2000, 626, 1317-1331; (b) R. M. Gschwind, Chem. Rev., 2008, 108, 3029-3053.

12 G. Whitesides, W. Fisher, J. San Filipo, R. Bashe and H. House, J. Am. Chem. Soc., 1969, 91, 4871-4882.

13 (a) B. H. Lipshutz, R. S. Wilhelm and D. M. Floyd, J. Am. Chem. Soc., 1981, 103, 7672-7674; (b) B. H. Lipshutz, S. Sharma and E. L. Ellsworth, J. Am. Chem. Soc., 1990, 112, 
4032-4034; (c) B. Lipshutz and B. James, J. Org. Chem., 1994, 59, 7585-7587.

14 (a) S. Bertz, J. Am. Chem. Soc., 1990, 112, 4031-4132; (b) J. Snyder, D. Spangler, J. Behling and B. Rossiter, J. Org. Chem., 1994, 59, 2665-2667; (c) J. Snyder and S. Bertz, J. Org. Chem., 1995, 60, 4312-4315; (d) T. L. Stemmler, T. M. Barnhart, J. E. Penner-Hahn, C. E. Tucker, P. Knochel, M. Bohme and G. Frenking, J. Am. Chem. Soc., 1995, 117, 12489-12497.

15 G. van Koten and J. G. Noltes, J. Am. Chem. Soc., 1979, 101, 6593-6605.

16 (a) G. van Koten and J. G. Noltes, J. Chem. Soc., Chem. Commun., 1972, 940-941; (b) G. van Koten, J. T. B. H. Jastrzebski, F. Muller and C. H. Stam, J. Am. Chem. Soc., 1985, 107, 697-698; (c) C. Kronenberg, J. Jastrzebski, A. Spek and G. van Koten, J. Am. Chem. Soc., 1998, 120, 9688-9689; (d) G. Boche, F. Bosold, M. Marsch and K. Harms, Angew. Chem., Int. Ed., 1998, 37, 1684-1686.

17 S. Usui, Y. Hashimoto, J. V. Morey, A. E. H. Wheatley and M. Uchiyama, J. Am. Chem. Soc., 2007, 129, 15102-15103.

18 P. J. Harford, A. J. Peel, J. P. Taylor, S. Komagawa, P. R. Raithby, T. P. Robinson, M. Uchiyama and A. E. H. Wheatley, Chem.-Eur. J., 2014, 20, 3908-3912.

19 S. Komagawa, S. Usui, J. Haywood, P. J. Harford, A. E. H. Wheatley, Y. Matsumoto, K. Hirano, R. Takita and M. Uchiyama, Angew. Chem., Int. Ed., 2012, 51, 12081-12085. 20 (a) N. Marquise, P. J. Harford, F. Chevallier, T. Roisnel, A. E. H. Wheatley, P. C. Gros and F. Mongin, Tetrahedron Lett., 2013, 54, 3154-3157; (b) N. Marquise, P. J. Harford, F. Chevallier, T. Roisnel, V. Dorcet, A.-L. Gagez, S. Sablé, L. Picot, V. Thiéry, A. E. H. Wheatley, P. C. Gros and F. Mongin, Tetrahedron, 2013, 69, 10123-10133.

21 A. J. Peel, M. Hedidi, G. Bentabed-Ababsa, T. Roisnel, F. Mongin and A. E. H. Wheatley, Dalton Trans., 2016, 45, 6094-6104.

22 J. Haywood, J. V. Morey, A. E. H. Wheatley, C.-Y. Liu, S. Yasuike, J. Kurita, M. Uchiyama and P. R. Raithby, Organometallics, 2009, 28, 38-41.

23 P. J. Harford, A. J. Peel, F. Chevallier, R. Takita, F. Mongin, M. Uchiyama and A. E. H. Wheatley, Dalton Trans., 2014, 43, 14181-14203.

24 (a) G. van Koten and J. G. Noltes, J. Am. Chem. Soc., 1979, 101, 6593-6605; (b) C. M. P. Kronenburg, J. T. B. H. Jastrzebski, J. Boersma, M. Lutz, A. L. Spek and G. van Koten, J. Am. Chem. Soc., 2002, 124, 11675-11683.

25 R. A. D. Soriaga, S. Javed and D. M. Hoffman, J. Cluster Sci., 2010, 21, 567-575.

26 T. P. Robinson, R. D. Price, M. G. Davidson, M. A. Fox and A. L. Johnson, Dalton Trans., 2015, 44, 5611-5619.

27 S. D. Bunge and J. L. Steele, Inorg. Chem., 2009, 48, 2701-2706. 28 C. Wagner and K. Merzweiler, Z. Anorg. Allg. Chem., 2014, 640, 2198-2202.

29 E. C. Franklin, Proc. Natl. Acad. Sci. U. S. A., 1915, 1, 68-70. 30 (a) S. Gambarotta, M. Bracci, C. Floriani, A. Chiesi-Villa and C. Guastini, J. Chem. Soc., Dalton Trans., 1987, 1883-1888; (b) H. Chen, M. M. Olmstead, S. C. Shoner and P. P. Power, J. Chem. Soc., Dalton Trans., 1992, 451-457; (c) A. M. James,
R. K. Laxman, F. R. Fronczek and A. W. Maverick, Inorg. Chem., 1998, 37, 3785-3791; (d) B. S. Lim, A. Rahtu, J.-S. Park and R. G. Gordon, Inorg. Chem., 2003, 42, 7951-7958. 31 (a) S. V. Ley and A. W. Thomas, Angew. Chem., Int. Ed., 2003, 42, 5400-5449; (b) G. Evano, N. Blanchard and M. Toumi, Chem. Rev., 2008, 108, 3054-3131; (c) F. Monnier and M. Taillefer, Angew. Chem., Int. Ed., 2009, 48, 6954-6971; (d) C. Sambiagio, S. P. Marsden, A. J. Blacker and P. C. McGowan, Chem. Soc. Rev., 2014, 43, 3525-3550.

32 E. Söderbäck, Acta Chem. Scand., 1957, 11, 1622-1634.

33 (a) K. Gregory, P. v. R. Schleyer and R. Snaith, Adv. Inorg. Chem., 1991, 37, 47-142; (b) R. E. Mulvey, Chem. Soc. Rev., 1991, 20, 167-209.

34 F. S. Mair, W. Clegg and P. A. O'Neil, J. Am. Chem. Soc., 1993, 115, 3388-3389.

35 P. L. Hall, J. H. Gilchrist, A. T. Harrison, D. J. Fuller and D. B. Collum, J. Am. Chem. Soc., 1991, 113, 9575-9585.

36 For $9 \mathbf{b}_{3}$ see: (a) E. Hevia, A. R. Kennedy, R. E. Mulvey, D. L. Ramsay and S. D. Robertson, Chem.-Eur. J., 2013, 19, 14069-14075. For general trimeric lithium amides see: $(b)$ D. R. Armstrong, R. E. Mulvey, G. T. Walker, D. Barr, R. Snaith, W. Clegg and D. Reed, J. Chem. Soc., Dalton Trans., 1988, 617-628; (c) D. R. Armstrong, K. W. Henderson, A. R. Kennedy, W. J. Kerr, F. S. Mair, J. H. Moir, P. H. Moran and R. Snaith, J. Chem. Soc., Dalton Trans., 1999, 4063-4068; (d) S. R. Dubberley, P. Mountford and N. Adams, Acta Crystallogr., Sect. E: Struct. Rep. Online, 2002, 58, m342; (e) R. M. Porter and A. A. Danopoulos, Dalton Trans., 2004, 2556-2562; (f) V. H. Gessner and C. Strohmann, Organometallics, 2010, 29, 1858-1861.

37 For $9 \mathbf{b}_{4}$ see: (a) M. F. Lappert, M. J. Slade, A. Singh, J. L. Atwood, R. D. Rogers and R. Shakir, J. Am. Chem. Soc., 1983, 105, 302-304; (b) ref. 36.

38 For general tetrameric lithium amides see: J. Jubb, P. Berno, S. Hao and S. Gambarotta, Inorg. Chem., 1995, 34, 3563-3566.

39 For trimeric copper amides see: B. S. Lim, A. Rahtu, J.-S. Park and R. G. Gordon, Inorg. Chem., 2003, 42, 7951-7958.

40 For $9 \mathbf{c}_{4}$ see: ref. 9. For general tetrameric copper amides see: (a) H. Hope and P. P. Power, Inorg. Chem., 1984, 23, 936-937; (b) S. Gambarotta, M. Bracci, C. Floriani, A. Chiesi-Villa and C. Guastini, J. Chem. Soc., Dalton Trans., 1987, 1883-1888.

41 J. Garcia-Àlvarez, D. V. Graham, E. Hevia, A. R. Kennedy and R. E. Mulvey, Dalton Trans., 2008, 1481-1486.

42 (a) W. Clegg, B. Conway, E. Hevia, M. D. McCall, L. Russo and R. E. Mulvey, J. Am. Chem. Soc., 2009, 131, 2375-2384; (b) S. Tamba, K. Ide, K. Shono, A. Sugie and A. Mori, Synlett, 2013, 24, 1133-1136.

43 D. R. Armstrong, R. David, P. Garcia-Alvarez, A. R. Kennedy, R. E. Mulvey, E. Robert and S. D. Robertson, Chem.-Eur. J., 2011, 17, 6725-6730.

44 T. Kottke and D. Stalke, J. Appl. Crystallogr., 1993, 26, 615619.

45 G. M. Sheldrick, Acta Crystallogr., Sect. A: Found. Crystallogr., 2015, 71, 3-8.

46 A. Altomare, G. Cascarano, C. Giacovazzo, A. Guagliardi, M. C. Burla, G. Polidori and M. Camalli, J. Appl. Crystallogr., 1994, 27, 435-436. 